\title{
Dependência de empregada: tradição nos edifícios de apartamentos do bairro Farol em Maceió, $\mathrm{AL}$
}

\author{
Maid's rooms: the tradition in the apartments buildings of \\ Farol district in Maceió, $A L$
}

\section{Jéssica Caroline Rodrigues de Lima Alexandre Márcio Toledo}

\section{Resumo}

A presença da empregada doméstica nos lares brasileiros de alta e média renda é um fator cultural. Com o crescente processo de verticalização, os edifícios de apartamentos incluíram a dependência de empregada no setor de serviço e com acesso distinto do social. O objetivo do presente artigo é traçar a trajetória da dependência de empregada nos edifícios multifamiliares altos construídos no tradicional bairro Farol (ZR 7 e ZR8), na cidade de Maceió, AL, durante o período de 1960 a 2010. Utilizou-se como banco de dados pesquisas realizadas pelo gEPA/FAU/UFAL. Observou-se que, nas décadas de 1960 e 1970, todos os apartamentos no bairro possuíam dependência de empregada; apenas na década de 1980 surgiu o primeiro edifício de apartamentos com dormitório reversível. Na década de 1990, a dependência de empregada permaneceu nas tipologias de apartamentos de 3 e 4 dormitórios e somente durante a década de 2000 surgiram os primeiros apartamentos sem dependência de empregada. Conclui-se que a presença da dependência de empregada prevaleceu sobre a oferta de apartamentos produzidos nas cinco décadas analisadas, e que as mudanças anunciadas pela legislação trabalhista de 1988 não alteraram ainda a oferta do mercado imobiliário para usuários de rendas mais elevadas.

Palavras-chave:Dependência de empregada. Edifício multifamiliar. Dormitório reversível. Tipologias de apartamentos.

\begin{abstract}
The presence of domestic employees in high and middle income Brazilian households is a cultural factor. With the increasing verticalisation process, apartment buildings included the maid's quartersin the service area, with a separate entrance. The aim of the present article is to trace a history of maids' quarters in high-rise apartment buildings built in the traditional neighbourhood of Farol (ZR 7 e ZR8) in the city of Maceió/AL, from 1960 to 2010. The database used were the surveys carried out by gEPA/FAU/UFAL. It was observed that, in

the 1960s and 1970s, all the apartments in the neighbourhood were dependent on maids; only in the 1980s did the first apartment building with a reversible maid's dormitory appear. In the 1990s, maids' quarters remained in the typologies of 3 and 4 bedroom apartments and only during the 2000s did the first apartments without maids'quarters appear. The study concluded that the presence of maids'rooms prevailed in the supply of apartments produced in the five decades analysed, and that the changes introduced by the 1988 labour legislation did not alter the offer of the real estate market for higher income users.
\end{abstract}

${ }^{1}$ Jéssica Caroline Rodrigues de

'Universidade Federal de Alagoas Maceió - AL - Brasil

${ }^{2}$ Alexandre Márcio Toledo ${ }^{2}$ Universidade Federal de Alagoas Maceió - AL - Brasil

Recebido em 03/12/19 Aceito em 05/03/20
Keywords: Maid's room. Multifamily buildings. Reversible dormitory. Apartment typologies. 


\section{Introdução}

Elemento tradicional nos programas de residências de famílias de classe média e alta no Brasil, a dependência de empregada consiste em um cômodo cuja adoção decorria, originalmente, da intenção de unificar os ambientes de trabalho e residência dessa profissional; e que produziu uma solução arquitetônica bastante peculiar: a disposição de um ambiente direcionado ao descanso dentro da área de serviço. Reduzidas ao extremo e escondidas dos olhos dos moradores e visitantes, por meio de uma configuração que promove o seu isolamento dos demais setores da habitação, esse ambiente carrega uma forte carga simbólica vinculada à lógica de pensamento escravocrata do período colonial e à estratificação social que marcou a construção da sociedade brasileira (MELLO, 2012).

As raízes do trabalho doméstico no sistema escravocrata e na divisão sexual do trabalho reforçaram a invisibilidade e o desprestígio social dessa atividade (ORGANIZAÇÃO..., 2010); aspectos que se refletiram no planejamento dos espaços da habitação ao longo de sua transformação. Para Bittar e Veríssimo (1999), a dependência de empregada constitui herança histórica das edículas do século XIX, alojamentos precários situados nos fundos dos lotes das residências e ocupados por escravos.

Carvalho (2003) e Souza (2010) discorrem sobre como o trabalho doméstico prestado por mulheres brancas livres e pobres ${ }^{1}$ coexistiu com a prestação desse serviço pelo escravo durante o século XIX, e que parte dessa categoria de trabalhadoras livres também residiu nas casas dos patrões, muitas vezes em condições similares às acomodações dos escravos.

As transformações significativas nos alojamentos de serviço teriam ocorrido de maneira tardia, a partir da abolição da escravatura, assinada em 1888. Com isso, a empregada assalariada ganhou acomodações decentes $^{2}$, dormitório e banheiro, não mais dormindo em construções improvisadas nos quintais, em porões abafados e úmidos, nos desvãos do telhado, ou em pseudodespensas, ao lado do fogão ${ }^{3}$; sendo, no entanto, tais ambientes mantidos próximos à área de serviço enquanto determinador da identificação funcional e social (LEMOS, 1978).

Nas plantas iniciais dos primeiros edifícios de apartamentos construídos no país a partir da década de 1920, a dependência de empregada continuou sendo acessada pelo setor de serviço com base na tripartição funcional da casa burguesa. Segundo Bittar e Veríssimo (1999), foi com o surgimento das habitações multifamiliares verticais que os ambientes de serviço atingiram dimensões mínimas e racionalização máxima, além de serem sempre dispostos nos locais menos confortáveis e de maior insolação da unidade habitacional em climas tropicais (COIMBRA et al., 2018).

A contratação de empregadas domésticas que residiam nas dependências de serviço foi, durante muito tempo, frequente nos lares brasileiros, sobretudo nas regiões nordeste e sudeste (INSTITUTO..., 2015), estando relacionada à contratação por valores baixos de mulheres em situação de vulnerabilidade social e econômica, muitas vezes migrantes de municípios do interior dos estados próximos, que encontravam no trabalho doméstico uma chance de inserção no mercado de trabalho urbano (LOPEZ, 2018).

No entanto, o estudo realizado pelo Instituto de Pesquisa Aplicada (2015) revelou que de 1995 a 2015 ocorreu no Brasil uma redução de $89 \%$ no número de empregadas formalizadas que moram no local de trabalho, e que, em contrapartida, a quantidade de diaristas passou por um aumento de 73,2\%. Dentre as hipóteses levantadas como possíveis razões para essas mudanças destaca-se o aumento dos valores pagos por esse serviço, decorrente da regulamentação dos direitos dos trabalhadores domésticos, garantida com a aprovação da lei n ${ }^{\circ} 5.859$ de $1972^{4}$; da promulgação da Constituição Federal de $1988^{5}$; e mais recentemente

\footnotetext{
${ }^{1}$ As atividades domésticas tendiam a atrair trabalhadores livres e pobres que não possuíam "qualificação" para atuar em outros locais de trabalho, sendo que no caso das mulheres livres somavam-se questões de restrição de gênero, uma vez que os códigos morais da época incentivavam o seu afastamento das atividades do meio público, o que tornava o trabalho doméstico quase a única alternativa de sobrevivência e autonomia de mulheres pobres (SOUZA, 2010).

2Essa requalificação tardia do "quarto de empregada" possivelmente teria ocorrido em grande parte devido ao maior padrão de exigência da mão de obra imigrante branca em relação às suas acomodações (SILVA, 2004).

${ }^{3}$ Antes da abolicão em 1888, também era possível encontrar em alguns exemplares de residências de famílias ricas quartos de criadas projetados dentro de casa, com comunicação interna, como se essas fossem agregadas à família, porém tal solução estaria relacionada à contratação de criadas estrangeiras brancas para atuar como preceptoras das crianças e como governantas, sendo os demais trabalhadores domésticos acomodados nos porões, nas mansardas ou em espaços ao lado da cozinha (LEMOS; SCHETTINO, 2014).

${ }^{4} \mathrm{~A}$ Lei n. 5859/72 limitou a fixar alguns poucos direitos como: 20 dias úteis de férias após 12 meses de serviço prestado à mesma pessoa ou família, carteira de trabalho e previdência social (CTPS) assinada pelo empregador, além de benefícios da previdência social (BRASIL, 1988).
}

8 Lima, J. C. R. de; Toledo, A. M. 
a Emenda Constitucional no 72, conhecida popularmente como "PEC das Domésticas" e aprovada em $2013^{6}$ - cuja regulamentação de muitos novos direitos veio com a aprovação da lei complementar n 150 de 2015 (BRASIL, 1988).

Além disso, pode-se citar a questão das transformações ocorridas no estilo de vida das famílias brasileiras, que ao passarem mais tempo fora de casa, e dispondo de uma cozinha e lavanderia cada vez mais dotadas de equipamentos que realizam parte do trabalho doméstico, preferem não contratar uma empregada mensalista. Segundo Coronato et al. (2012), um número crescente de pessoas passa a se sentir desconfortável com o tipo de relação autoritária e assistencialista cultivada com as empregadas ao longo das décadas anteriores, a qual se mostra invasiva para ambos os lados.

Apesar das mudanças ocorridas no universo jurídico e prático do trabalho doméstico, no campo da arquitetura, os espaços de uso específico da empregada doméstica permanecem em grande parte das residências do país, situação observada por Brandão (2002), que constatou a predominância da tipologia de três dormitórios com dependência de empregada, com base em 3.000 plantas de apartamentos, de empreendimentos lançados entre 1995 e 2000 de 50 cidades brasileiras.

Por outro lado, esses ambientes vêm agregando novas possibilidades de utilização pelos moradores, situação verificada no estudo etnográfico de Goldstein (2003) realizado no Rio de Janeiro. A autora discorre sobre como o "quartinho", situado invariavelmente atrás da cozinha e da lavanderia, passou de moradia a espaço para uso apenas durante o dia, mediante seu "aproveitamento" como depósito de tudo que deve permanecer escondido para não desordenar a casa, transformando-o em um "quarto de despejo". Nos edifícios de apartamentos, essa problemática tende a ser ainda mais intensificada, em virtude de sua configuração espacial, essencialmente mais compacta, quando comparada às residências unifamiliares.

A redução de situações de empregadas que continuam a dormir no local do emprego também tem ocasionado a transformação da dependência em extensão da área de serviço, despensa, ou até mesmo em um novo dormitório para um dos familiares, escritório ou closet, configurando nesses últimos casos, possivelmente, o chamado dormitório reversível (TRAMONTANO; VILLA, 2000; MORAIS, 2017). Segundo Saleiro Filho (2001), para o morador a dependência reversível de empregada possibilita a ampliação do espaço pessoal/privado da família, por meio da introdução de um ambiente quepoderia ser, setorialmente, segregado, mas que lhe dá a ilusão de estar acrescendo mais um compartimento aos setores de sua habitação.

Em Maceió, capital do estado de Alagoas, o processo de verticalização aconteceu tardiamente, sendo iniciado somente a partir da década de 1960 com o surgimento dos primeiros edifícios residenciais multifamiliares em altura nos bairros Centro e Farol. Esse processo se consolidou durante as décadas de 1970 e $1980^{7}$, motivado pela instalação das primeiras construtoras na cidade e pelo desejo da classe média e alta em superar a sensação de "atraso" com relação às grandes metrópoles brasileiras a partir da adoção de seus hábitos de morar (ALVES, 2012, SANTOS, 2016).

Nesse período, o bairro Farol, localizado na parte alta da cidade, cujo nome se deve à instalação do primeiro farol portuário, já era conhecido como "bairro da elegância" ou "reduto do granfinismo" em virtude de sua ocupação pelas classes sociais mais abastadas, ocorrida no início do século XX, devido a fatores como salubridade, amenidade do clima e proximidade do centro comercial da cidade (FORTES, 2011). Com o surgimento e intensificação da construção de edifícios altos de apartamentos no bairro, que compreende duas zonas residenciais (ZR7 e ZR8), até o final do século XX, a horizontalidade homogênea cedeu lugar a trechos verticalizados, gerando uma paisagem heterogênea e dinâmica (SANTOS, 2016).

Segundo Barros (2014), foi com o desenvolvimento e a ocupação dos bairros da orla litorânea da cidade que o bairro Farol foi perdendo espaço na preferência das construtoras e de parte da população maceioense. Atualmente, com o gradativo esgotamento de terrenos para construção na orla, os terrenos do bairro Farol, sobretudo os localizados às margens da encosta, voltaram a ser valorizados pelas imobiliárias para a

${ }^{5}$ A Constituição de 1988 garantiu o direito ao salário mínimo nacionalmente unificado, ao décimo terceiro salário com base na remuneração integral, repouso semanal remunerado, férias anuais remuneradas com, pelo menos, um terço a mais do que o salário normal, entre outros direitos (BRASIL, 1988).

${ }^{6} \mathrm{~A}$ Emenda Constitucional $\mathrm{n}^{\circ} 72$ fez surgir inúmeras regulamentações como o pagamento de adicional noturno, adicional de viagem, banco de horas e controle de ponto, Fundo de Garantia de Tempo de Serviço (FGTS), redução do INSS do empregador para $8 \%$, seguro acidente de trabalho, entre outros (BRASIL, 1988).

${ }^{7} O$ primeiro código de edificações de Maceió que trata de edifícios verticais foi implantado pela Lei n. 2.624, de 9 de outubro de 1979 , passando a contemplar itens específicos sobre edifícios multifamiliares em altura somente em 1985, quando foi reformulado pela Lei n. 3.537, de 23 de dezembro de 1985 (TOLEDO; SILVA; BARBOSA, 2015). 
construção de edifícios verticais de alto padrão, sendo exaltada pelo marketing a posição topográfica privilegiada do bairro que, em alguns locais, possibilita a visão da orla litorânea e por isso transforma os edifícios ali instalados nos chamados "novos beira-mar", e a comodidade promovida pela infraestrutura completa de serviços existentes na área (SANTOS, 2016).

Desse modo, o bairro Farol consiste em uma área da capital ocupada, em geral, por uma camada da população de renda média e alta, e cuja opção por morar em apartamentos vem sendo intensificada ao longo das últimas décadas. Cabe destacar que a cidade de Maceió há muito tempo tem sido alvo de um intenso fluxo migratório de pessoas oriundas de municípios pobres do Estado (reflexo da desigualdade social e econômica entre as regiões de Alagoas), sendo que grande parte das mulheres desse grupo, de pouca escolaridade, insere-se no trabalho doméstico, o que colaborou para a existência, por muito tempo, de uma mão de obra bastante ampla, precária, e barata, que tinha na moradia na casa dos patrões, por vezes a única opção para se manter na capital (LOPEZ, 2018). Esse quadro possivelmente colaborou para que a contratação de empregadas se tornasse um hábito de morar da população alagoana, sobretudo de famílias de bairros tradicionalmente residenciais como o Farol.

Tendo em mente que a presença da empregada doméstica nas residências brasileiras constitui um fator cultural, sobretudo nas famílias nordestinas de renda média e alta, o presente artigo tem como objetivo traçar uma trajetória projetual da dependência de empregada nos edifícios de apartamentos construídos no bairro Farol, na cidade de Maceió, no estado de Alagoas, durante as décadas de 1960 a 2000, visando melhor compreender como se deu a oferta desse produto pelo mercado imobiliário.

\section{Método}

Utilizaram-se como banco de dados pesquisas realizadas pelo Grupo de Estudos em Projeto de Arquitetura (gEPA/FAU) da Universidade Federal de Alagoas, que conta com um levantamento sistematizado de plantas baixas de quase 300 edifícios multifamiliares verticais altos (com mais de quatro pavimentos e elevador) construídos na cidade de Maceió até o ano de 1999; além de mais de 200 edifícios contemporâneos. O trabalho envolveu pesquisa quali-quantitativa, mediante análise das plantas de 45 edifícios verticais multifamiliares de diversas tipologias de apartamentos construídos no bairro Farol em Maceió (Figuras 1 e 2), do ano de 1964 até o ano de 2010 (Tabela 1).

Foram também levantadas informações relativas ao padrão construtivo ${ }^{8}$ dos edifícios do universo da pesquisa na plataforma digital da Secretaria Municipal de Economia (Semec) da Prefeitura de Maceió, que disponibiliza a consulta do número de inscrição e o acesso à ficha cadastral dos imóveis construídos na cidade de Maceió.

Com base nesse banco de dados, analisaram-se as dependências de empregada dos edifícios de apartamentos desse período, por meio de seis critérios (LIMA; TOLEDO, 2018):

(a) tipologias, considerando as variações dos apartamentos produzidos; os padrões construtivos dos edifícios (popular, médio baixo, médio, médio alto, alto e luxo) ${ }^{9}$; e a presença ou não da dependência de empregada e do dormitório reversível.

(b) localização do dormitório de empregada na planta, formas de acesso e flexibilidade de abertura para outras zonas ou setores do apartamento.

(c) áreas dos dormitórios de empregada, tendo como padrão mínimo 6 m² (NEUFERT, 2008; MACEIÓ..., 1985).

(d) tipos de aberturas adotados no dormitório de empregada.

(e) localização dos banheiros de serviço em relação ao dormitório de empregada (ao lado, em forma de suíte, afastado do dormitório e mista) e respectivas áreas, tendo como padrão mínimo $2 \mathrm{~m}^{2}$.

(f) caracterização das entradas dos apartamentos e elevadores dos edifícios(quantidade, existência de diferenciação de uso social e serviço e disposição na planta).

${ }^{8} \mathrm{~A}$ caracterização dos padrões considera 11critérios com diferentes variações, determinados pela Prefeitura de Maceió: tipo de estrutura; alvenaria; revestimento externo; revestimento interno da parede e do teto; piso; pintura externa e interna; esquadrias; coberta; elemento complementar para construção vertical/especial.

${ }^{9} \mathrm{~A}$ caracterização desses padrões obedece a um conjunto de 11 critérios com diferentes variações, determinados pela Prefeitura de Maceió: tipo de estrutura; alvenaria; revestimento externo; revestimento interno da parede; revestimento interno do teto; piso; pintura externa; pintura interna; esquadrias; coberta; elemento complementar para construção vertical/especial.

10 Lima, J. C. R. de; Toledo, A. M. 
A Categoria mista refere-se aos casos de edifícios cujas unidades de apartamentos apresentam mais de uma forma de dispor o espaço do dormitório de empregada ou o banheiro de serviço.

\section{Resultados e discussões}

Observou-se uma constante na produção de edifícios multifamiliares altos nas décadas de 1970, 1980 e 1990, e uma intensificação da produção na década de 2000.

\section{Décadas de 1960 e 1970}

\section{Tipologias e padrões construtivos dos edifícios}

Durante as décadas de 1960 e 1970 identificou-se a construção de 8 edifícios multifamiliares verticais altos no bairro Farol, todos dotados de dormitório de empregada, e com prevalecimento da tipologia de 3 dormitórios (5 unidades - 62,5\%) (Figuras 3 e 4). Durante esse período foi construído apenas um edifício de tipologia híbrida, composto por apartamentos de dois e de três quartos (Figura 5). Além disso, a maioria dos exemplares apresentou padrão construtivo médio (5 unidades - 62,5\%), sendo os demais de padrão construtivo médio alto.

\section{Figura 1 - Mapa da cidade de Maceió com destaque para o bairro Farol}

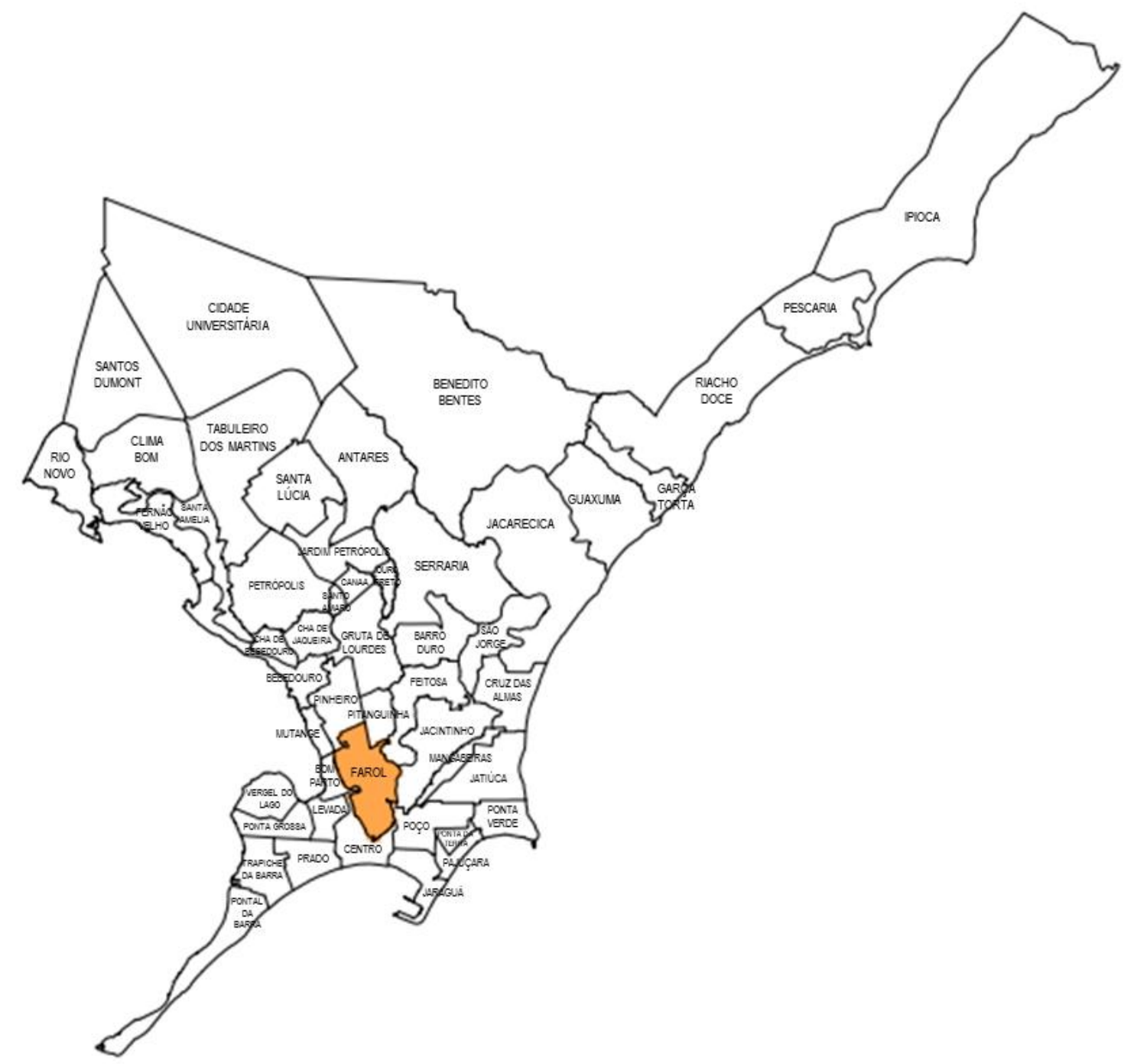

Fonte: adaptado de Lima (2019). 
Figura 2 - Mapa do bairro Farol com marcação dos edifícios de apartamentos verticais altos

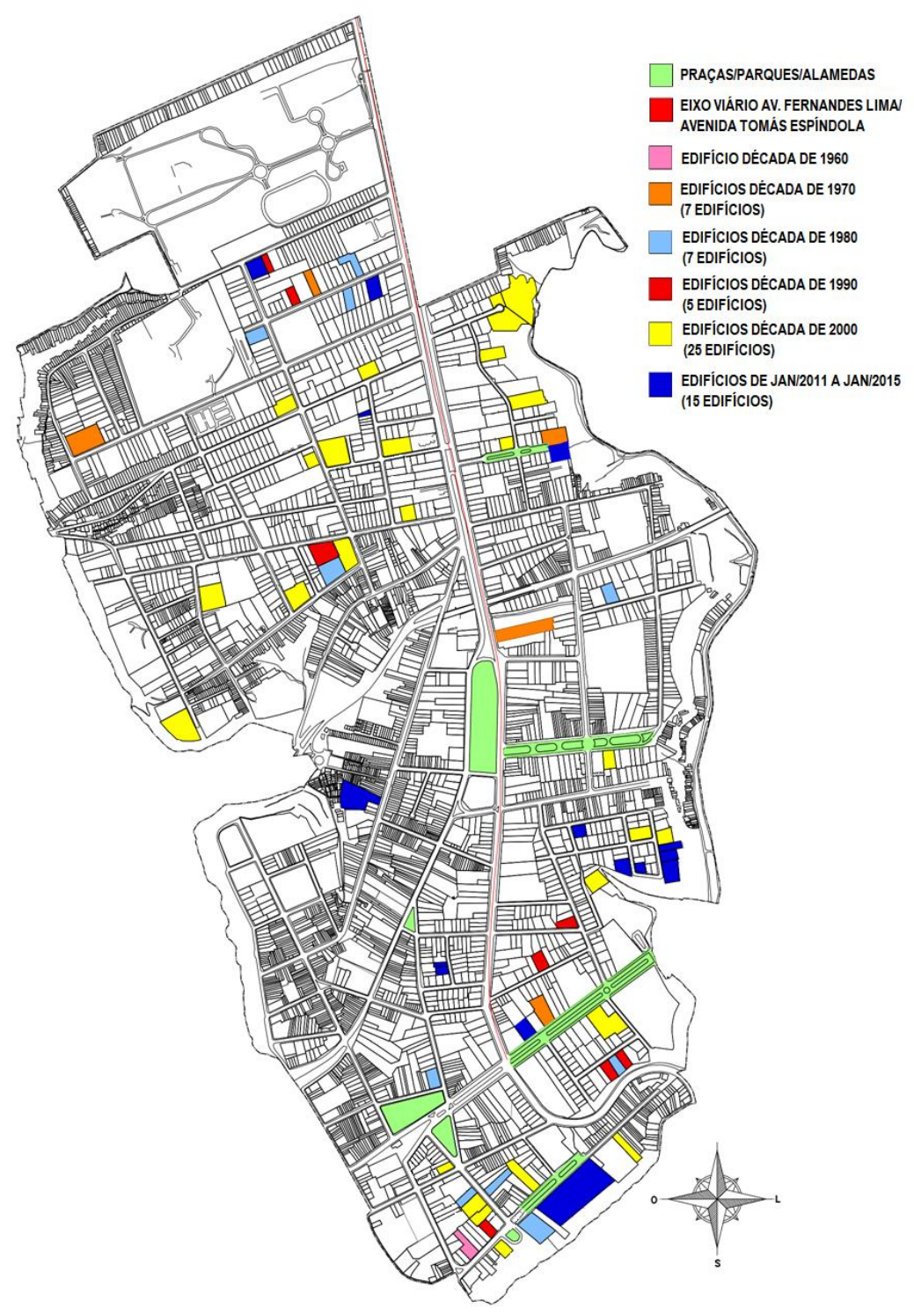

Fonte: Santos (2016).

Tabela 1 - Tipologias de apartamentos no bairro Farol: décadas de 1960 a 2000

\begin{tabular}{c|c|c|c|c|c|c}
\hline \multirow{2}{*}{ TIPOLOGIA } & \multicolumn{7}{|c|}{ DÉCADAS } & \multirow{2}{*}{ TOTAL } \\
\cline { 2 - 6 } & $\mathbf{1 9 6 0}$ & $\mathbf{1 9 7 0}$ & $\mathbf{1 9 8 0}$ & $\mathbf{1 9 9 0}$ & $\mathbf{2 0 0 0}$ & \\
\hline 2 DO + DE & 0 & 1 & 1 & 0 & 0 & $\mathbf{2}$ \\
2 DO + REV & 0 & 0 & 1 & 0 & 1 & $\mathbf{2}$ \\
3 DO & 0 & 0 & 0 & 0 & 2 & $\mathbf{2}$ \\
3 DO + DE & 0 & 5 & 5 & 4 & 7 & $\mathbf{2 1}$ \\
3 DO + REV & 0 & 0 & 0 & 0 & 2 & $\mathbf{2}$ \\
4 DO + DE & 1 & 0 & 0 & 1 & 6 & $\mathbf{8}$ \\
HÍB & 0 & 0 & 0 & 0 & 2 & $\mathbf{2}$ \\
HÍB + DE & 0 & 1 & 0 & 0 & 5 & $\mathbf{6}$ \\
\hline TOTAL POR DÉCADA & $\mathbf{1}$ & $\mathbf{7}$ & $\mathbf{7}$ & $\mathbf{5}$ & $\mathbf{2 5}$ & $\mathbf{4 5}$ \\
\hline
\end{tabular}

Nota: Legenda:

DO=Dormitório;

$\mathrm{DE}=$ Dependência de empregada;

REV=Dormitório reversível; e

HIB=Edifício dotado de 2 ou mais tipologias de apartamentos no pavimento tipo (híbrido).

12 Lima, J. C. R. de; Toledo, A. M. 
Figura 3 - Tipologias de apartamentos no bairro Farol: 1964 a 1979

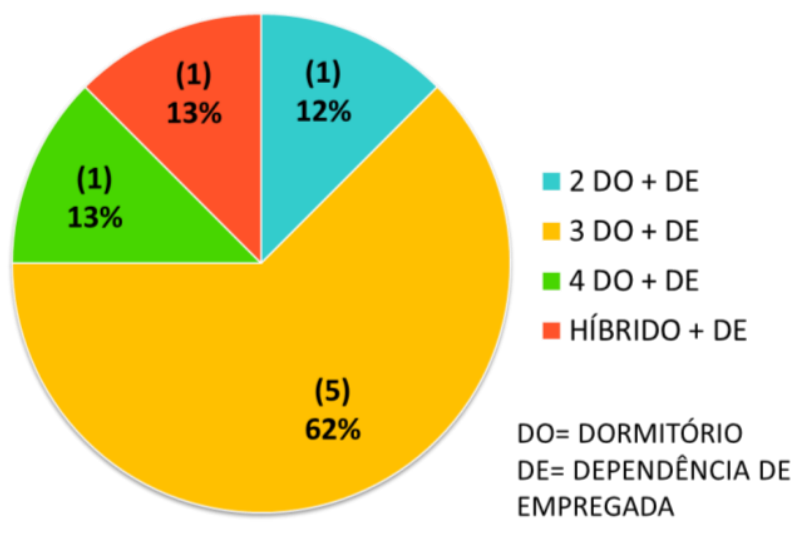

Figura 4 - Planta baixa de unidade do edifício Dom Avelar (1977)

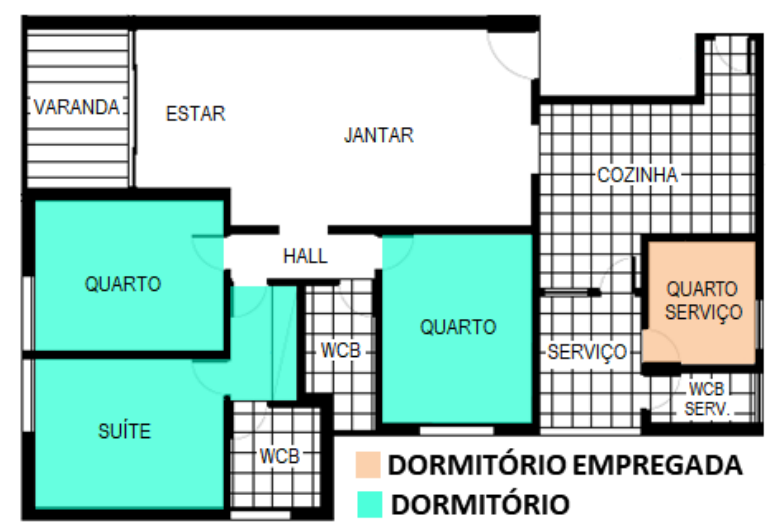

Fonte: adaptado do banco de dados do gEPA.

Nota: sem escala.

Figura 5 - Planta baixa de unidade do edifício Mykonos (1977)

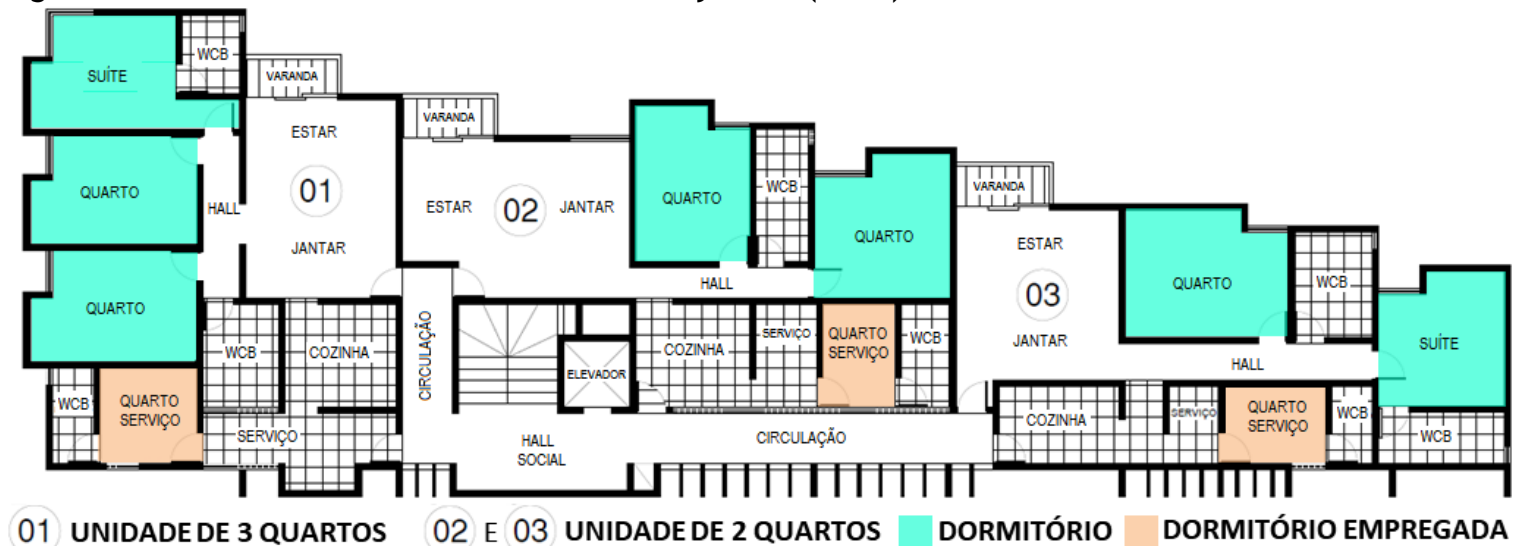

Fonte: adaptado do banco de dados do gEPA.

Nota: sem escala.

\section{Localização, acesso e flexibilidade de abertura dos dormitórios de empregada}

Na maioria dos casos o dormitório de empregada foi alocado no setor de serviço e junto à área de serviço, sendo exceção o caso do edifício Benedito Bentes de 1977, cujo dormitório de empregada encontrava-se junto à cozinha (Figura 6). O dormitório de empregada apresentou acesso através de passagem obrigatória pela cozinha e/ou pela área de serviço em quase todos os exemplares (Figura 7), sendo exceção apenas os 
apartamentos do edifício Armando Lobo de 1978, nos quais o acesso a esse ambiente é realizado de forma mais direta, por um hall interno ligado à porta de serviço da unidade (Figura 8).

Somente no edifício Boca da Grota de 1979 (Figura 9), observou-se a possibilidade de abertura do dormitório de empregada para ambiente de outro setor do apartamento, sendo nesse caso o corredor que permite o acesso aos dormitórios.

\section{Áreas dos dormitórios de empregada}

Quase todos os edifícios desse período apresentaram dormitórios de empregadas com áreas inferiores ao padrão mínimo de 6 m²$^{2}$, sendo exceção apenas o edifício Mansão Leonardo da Vinci de 1975 (Figura 10). Verificou-se nos apartamentos do edifício Lagoa Mar de 1964 o dormitório de empregada com menor área desse período $\left(3,5 \mathrm{~m}^{2}\right)$ (Figura 11).

Figura 6 - Planta baixa de unidade do edifício Benedito Bentes (1977)

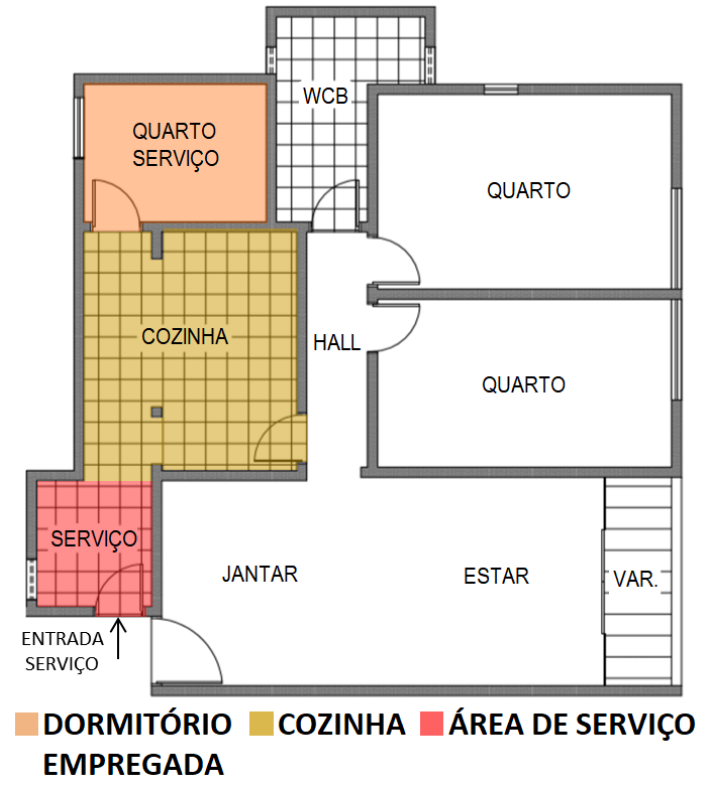

Fonte: adaptado do banco de dados do gEPA.

Nota: sem escala.

Figura 7 - Planta baixa de unidade do edifício Morada do Farol (1976)

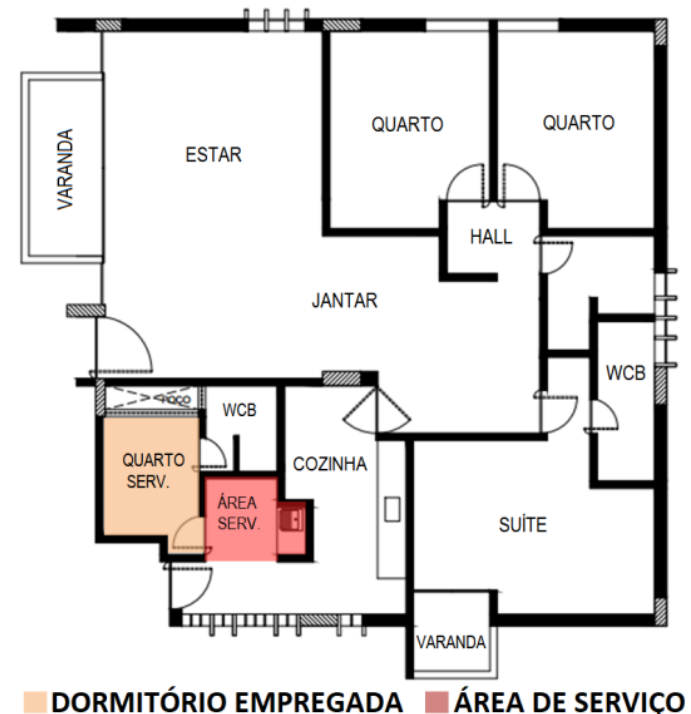

Fonte: adaptado do banco de dados do gEPA.

Nota: sem escala.

14 Lima, J. C. R. de; Toledo, A. M. 
Figura 8 - Planta baixa de unidade do edifício Armando Lobo (1978)

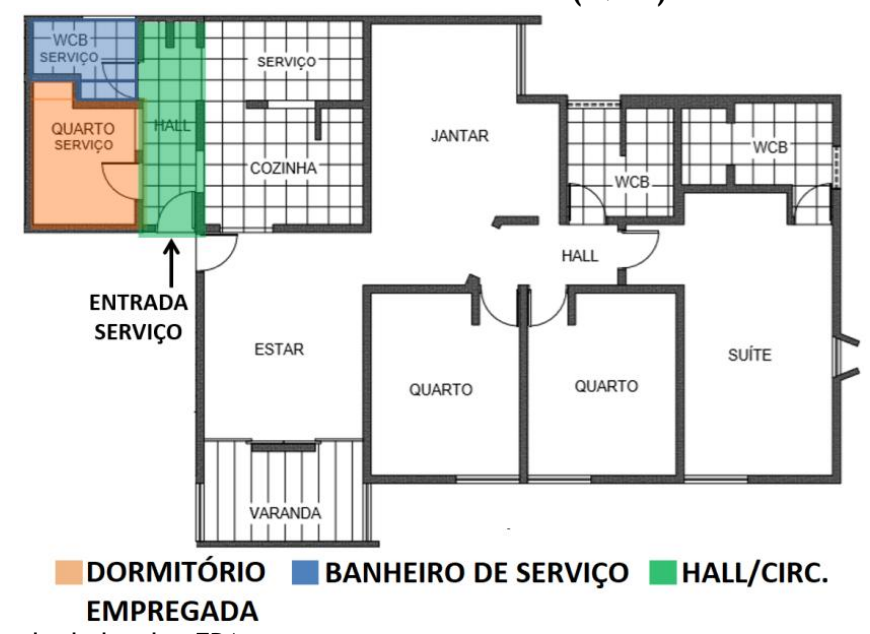

Fonte: adaptado do banco de dados do gEPA.

Nota: sem escala.

Figura 9 - Planta baixa de unidade do edifício Boca da Grota (1979)

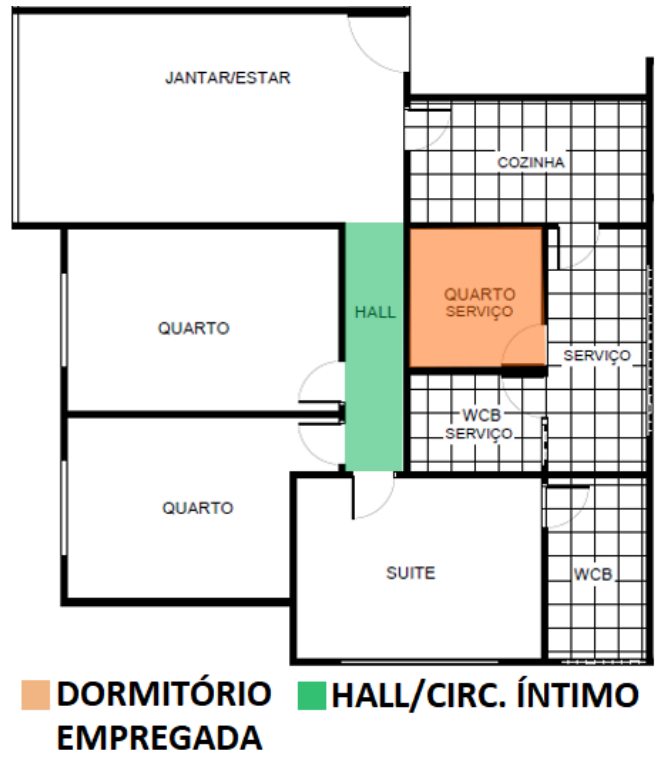

Fonte: adaptado do banco de dados do gEPA.

Nota: sem escala. 
Figura 10 - Planta baixa de unidade do edifício Mansão Leonardo da Vinci (1975)

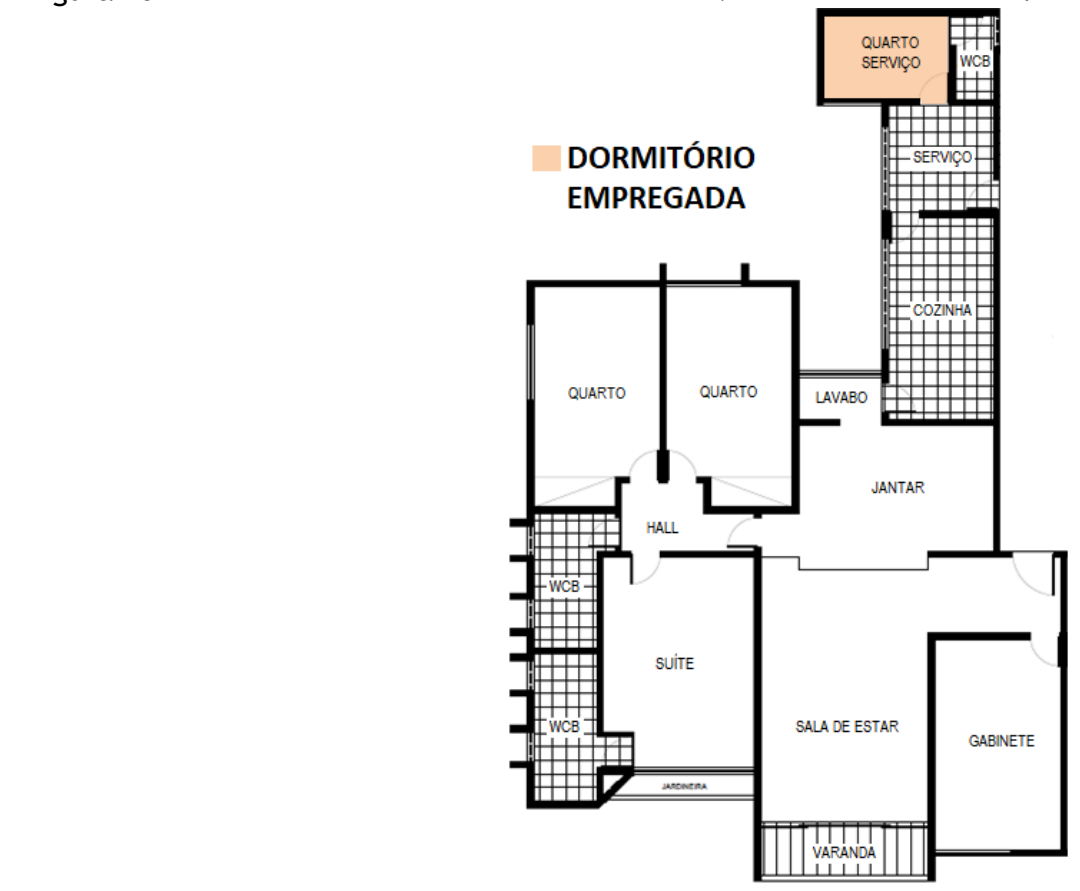

Fonte: adaptado do banco de dados do gEPA.

Nota: sem escala.

Figura 11 - Planta baixa de unidade do edifício Lagoa Mar (1964)

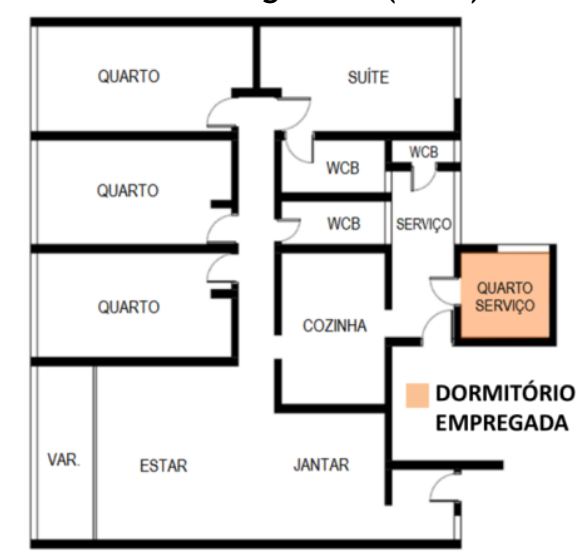

Fonte: adaptado do banco de dados do gEPA.

Nota: sem escala.

\section{Aberturas dos dormitórios de empregada}

$\mathrm{Na}$ maioria dos casos verificou-se a existência de dormitórios de empregada dotados de uma única janela com abertura para o exterior (4 unidades - 50\%), seguido pelos exemplares compostos por janela com abertura para o interior da área de serviço ou para um hall interno ( 2 unidades $-25 \%$ ), com janela aberta para um poço de ventilação ( 1 unidade - 12,5\%), e situação mista (1 unidade - $12,5 \%$ ).

\section{Localização e áreas dos banheiros de serviço}

Com exceção ao edifício Benedito Bentes de 1977 (Figura 6), todos os demais edifícios desse período apresentaram banheiro de serviço (constituindo dependência completa), sendo este disposto em forma de suíte (3 unidades $-42,9 \%$ ), ao lado do dormitório (3 unidades $-42,9 \%$ ), e afastado do dormitório (1 unidade - 14,2\%). Na maior parte dos casos os banheiros de serviço apresentaram dimensões dentro do padrão de 2 $\mathrm{m}^{2}$ (4 unidades -57,1\%). O edifício Lagoa Mar de 1964 apresentou os menores banheiros desse período (0,7 $\mathrm{m}^{2}$ ).

16 Lima, J. C. R. de; Toledo, A. M. 


\section{Caracterização das entradas e elevadores dos edifícios}

A maioria dos edifícios apresentou apartamentos dotados de porta social e de serviço (7 unidades $-87,5 \%)$, sendo essas dispostas em halls totalmente separados (2 unidades); portas separadas, porém com o mesmo hall de circulação ( 2 unidades); porta social e de serviço lado a lado (2 unidades) e situação mista (1 unidade). Somente no edifício Boca da Grota foram observados apartamentos dotados de porta externa única (Figura 12).

A maioria dos edifícios contou com elevadores diferenciados pelo uso social e serviço (6 unidades $-75 \%$ ), sendo esses distribuídos igualmente em 3 categorias: elevadores dispostos totalmente separados em halls independentes ( 2 unidades); elevadores alocados em halls distintos, porém interligados (2 unidades) (Figura 13); elevadores posicionados próximos no mesmo hall ( 2 unidades). Apenas 2 exemplares apresentaram elevador único.

Figura 12 - Planta baixa de pavimento tipo do edifício Boca da Grota (1979)

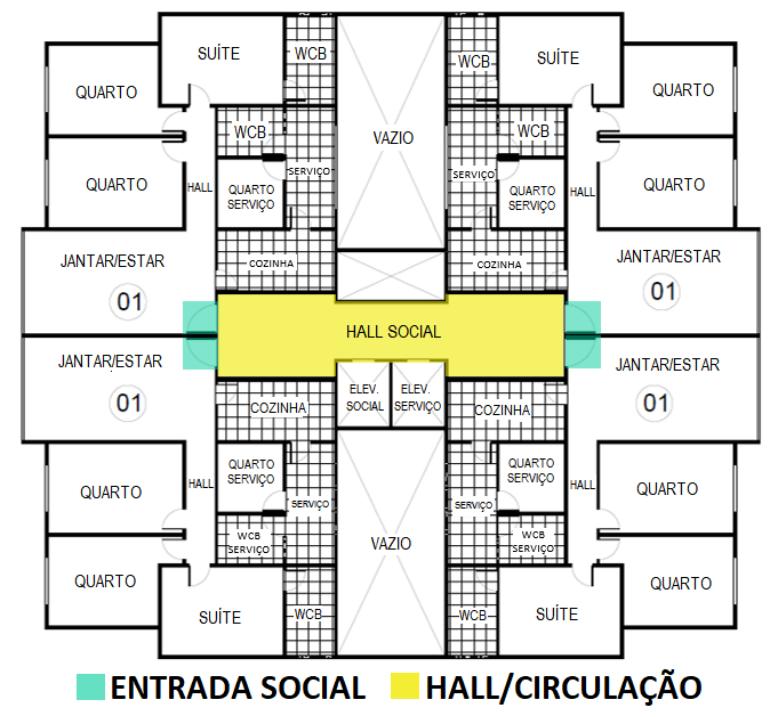

Fonte: adaptado do banco de dados do gEPA.

Nota: sem escala.

Figura 13 - Planta baixa de pavimento tipo do edifício Mansão Leonardo da Vinci (1975)

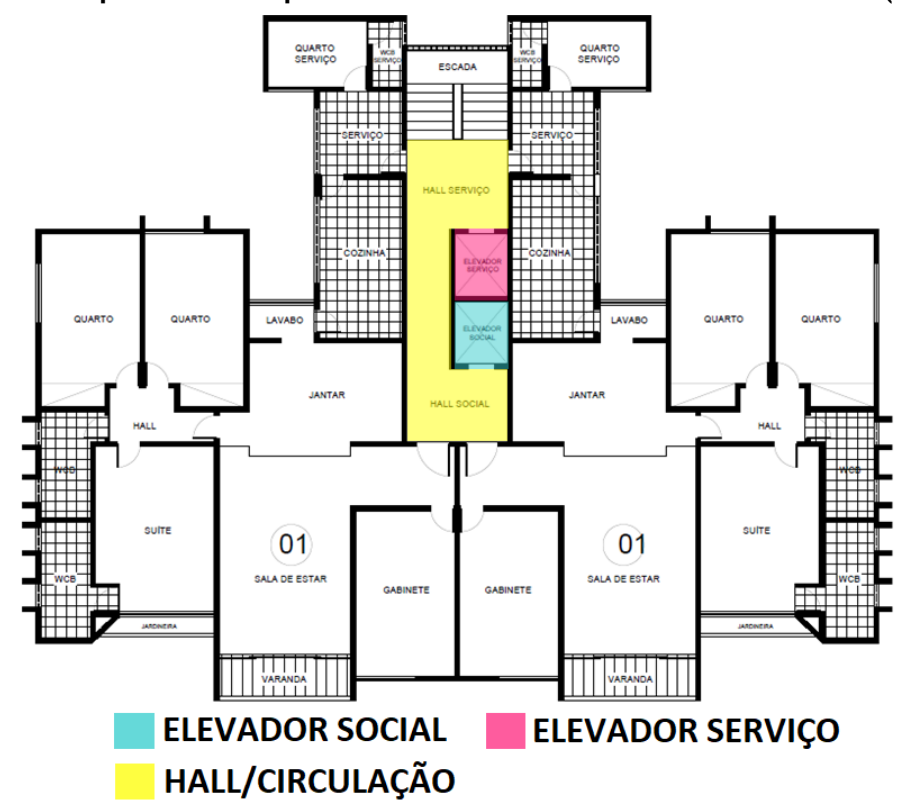

Fonte: adaptado do banco de dados do gEPA.

Nota: sem escala. 


\section{Década de 1980}

\section{Tipologias e padrões construtivos dos edifícios}

Durante a década de 1980, foram construídos 7 edifícios de apartamentos no bairro, sendo uma produção majoritariamente marcada pela tipologia de 3 dormitórios com dependência de empregada (5 unidades $71,4 \%$ ) conforme Figura 14. No ano de 1982 foi lançado o primeiro edifício com apartamentos dotados do dormitório reversível, o edifício Morada dos Ventos II (Figura 15). Ademais, a maior parte dessa produção apresentou padrão construtivo médio (4 unidades - 57,1\%), sendo os demais exemplares pertencentes à categoria média alta.

\section{Localização, acesso e flexibilidade de abertura dos dormitórios de empregada}

Nesse período, o dormitório de empregada foi mantido no setor de serviço, com acesso realizado obrigatoriamente pela área de serviço e, na maioria dos casos, com impossibilidade de abertura para os demais setores do apartamento, sendo exceção o edifício Gisele de 1982 (Figura 16), cujo dormitório de empregada apresenta flexibilidade de abertura para o setor social; e o edifício Porto Ferrario de 1987 (Figura 17), com possibilidade de abertura do dormitório de empregada para o setor íntimo.

Figura 14 - Tipologias de apartamentos no bairro Farol: 1980 a 1989

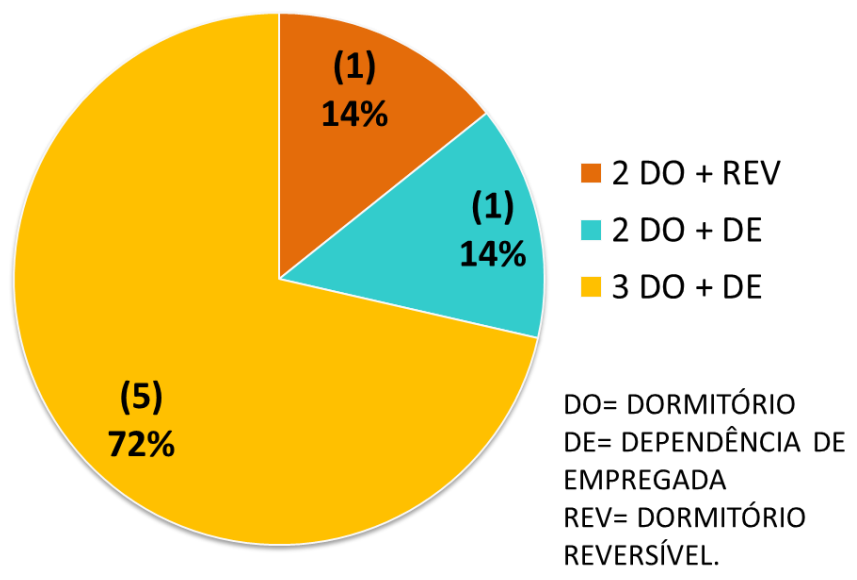

Figura 15 - Planta baixa de unidade do edifício Morada dos Ventos (1982)

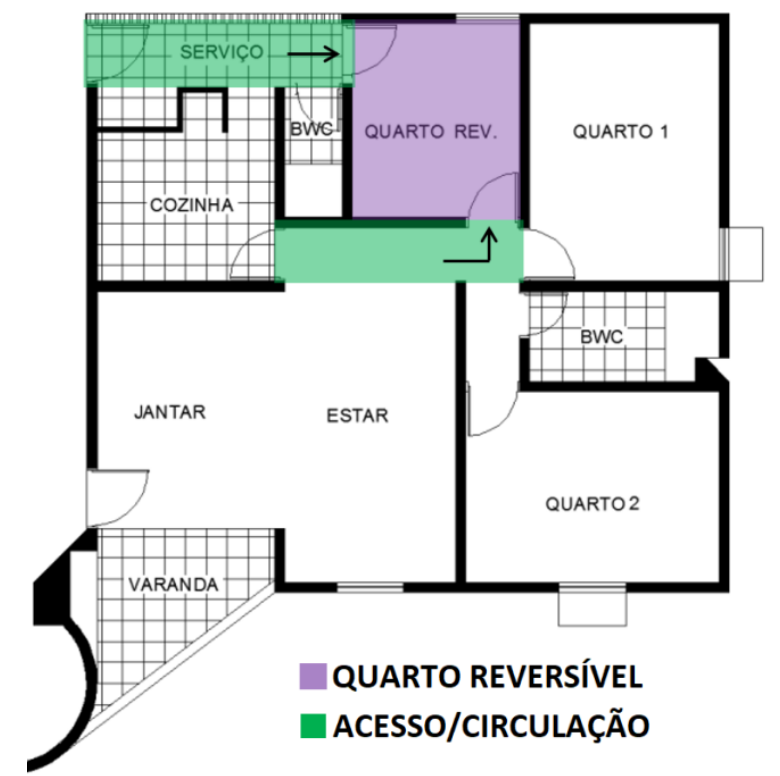

Fonte: adaptado do banco de dados do gEPA.

Nota: sem escala.

18 Lima, J. C. R. de; Toledo, A. M. 
Figura 16 - Planta baixa de unidade do edifício Gisele (1982)

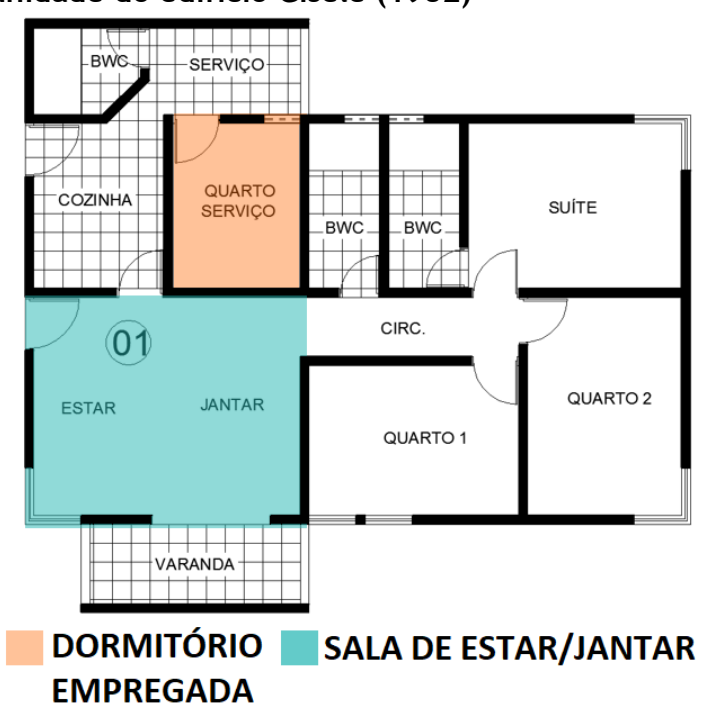

Fonte: adaptado do banco de dados do gEPA.

Nota: sem escala.

Figura 17 - Planta baixa de unidade do edifício Porto Ferrario (1987)

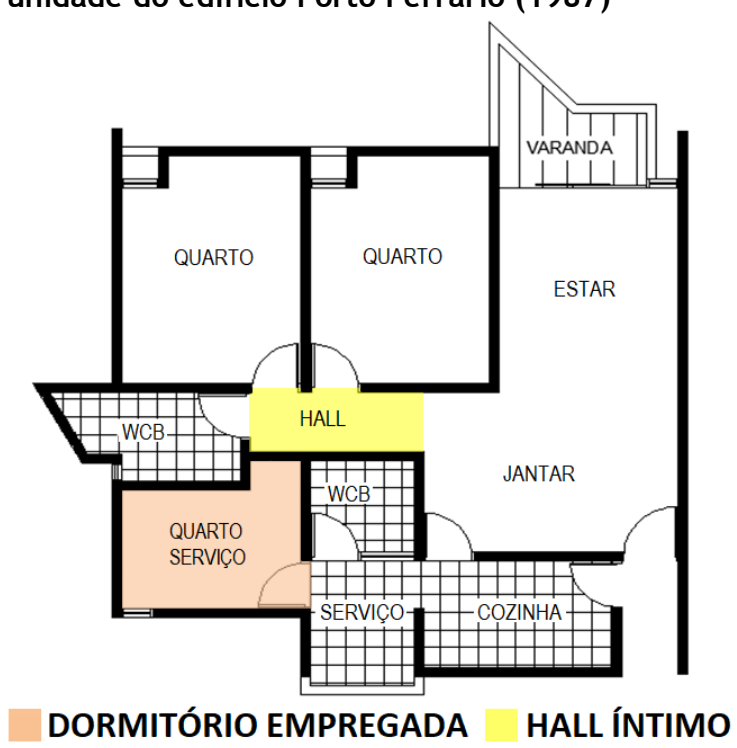

Fonte: adaptado do banco de dados do gEPA.

Nota: sem escala.

\section{Áreas dos dormitórios de empregada}

Todos os dormitórios de empregadas desse período apresentaram área dentro do padrão de 6 m².

\section{Aberturas dos dormitórios de empregada}

Na maioria dos casos verificou-se a existência de dormitórios de empregada dotados de uma única janela com abertura para o exterior (4 unidades $-66,7 \%$ ), seguido pelos exemplares compostos por janela com abertura para o interior da área de serviço (2 unidades $-33,3 \%)$.

\section{Localização e áreas dos banheiros de serviço}

Todos os edifícios produzidos durante os anos 1980 apresentaram unidades de apartamentos dotados de banheiro de serviço (incluindo o edifício Morada dos Ventos, único dotado de dormitório reversível). 
Considerando apenas a categoria de edifícios cujo programa contemplava o dormitório de empregada, verificou-se que o banheiro de serviço na maior parte das vezes foi alocado como suíte (3 unidades - 50\%), seguido pelos casos em que esse foi disposto ao lado do dormitório ( 2 unidades $-33,3 \%$ ) e casos de situação mista (1 unidade - 16,7\%) (Figura 18). Em todos os exemplares os banheiros de serviço apresentaram dimensões dentro do padrão de $2 \mathrm{~m}^{2}$.

\section{Caracterização das entradas e elevadores dos edifícios}

Todos os edifícios de apartamentos com dormitório de empregada construídos nos anos 1980 no Farol apresentaram apartamentos dotados de porta social e de serviço, sendo estas dispostas lado a lado (3 unidades - 50\%), separadas, porém, com o mesmo hall de circulação (2 unidades - 33,3\%), e em halls totalmente separados (1 unidade - 16,7\%) (Figura 19).

$\mathrm{O}$ atributo de diferenciação entre uso social e serviço também foi utilizado nos elevadores de todos os edifícios dessa década, sendo predominante a categoria de elevadores dispostos em halls distintos, porém interligados (3 unidades), seguido pelos elevadores posicionados próximos no mesmo hall (2 unidades) e pelos elevadores separados em halls totalmente independentes (1 unidade). O edifício Morada dos Ventos II, único de apartamentos dotados de dormitório reversível, conta com porta social e porta de serviço, e elevador único.

\section{Década de 1990}

\section{Tipologias e padrões construtivos dos edifícios}

Durante a década de 1990 foram construídos 5 edifícios no bairro, sendo todos dotados de dependência de empregada e com a predominância da tipologia de 3 dormitórios (4 unidades - 80\%) conforme Figura 20. O edifício Porchat foi o único exemplar desse período construído na tipologia de 4 dormitórios (Figura 21). Quase todos os edifícios apresentaram padrão construtivo médio alto, sendo exceção apenas um único edifício de padrão construtivo médio.

\section{Localização, acesso e flexibilidade de abertura dos dormitórios de empregada}

Assim como nas três décadas anteriores, o dormitório de empregada foi mantido no setor de serviço, com acesso realizado pela área de serviço (Figura 22). Os dormitórios de empregada desse período apresentaram possibilidade de abertura para os setores social e íntimo em 2 edifícios (40\%) (Figura 23), situação mista em 2 unidades $(40 \%)$, e impossibilidade de abertura para outros setores em 1 unidade $(20 \%)$.

Figura 18 - Planta baixa do pavimento tipo do edifício Junco (1983)

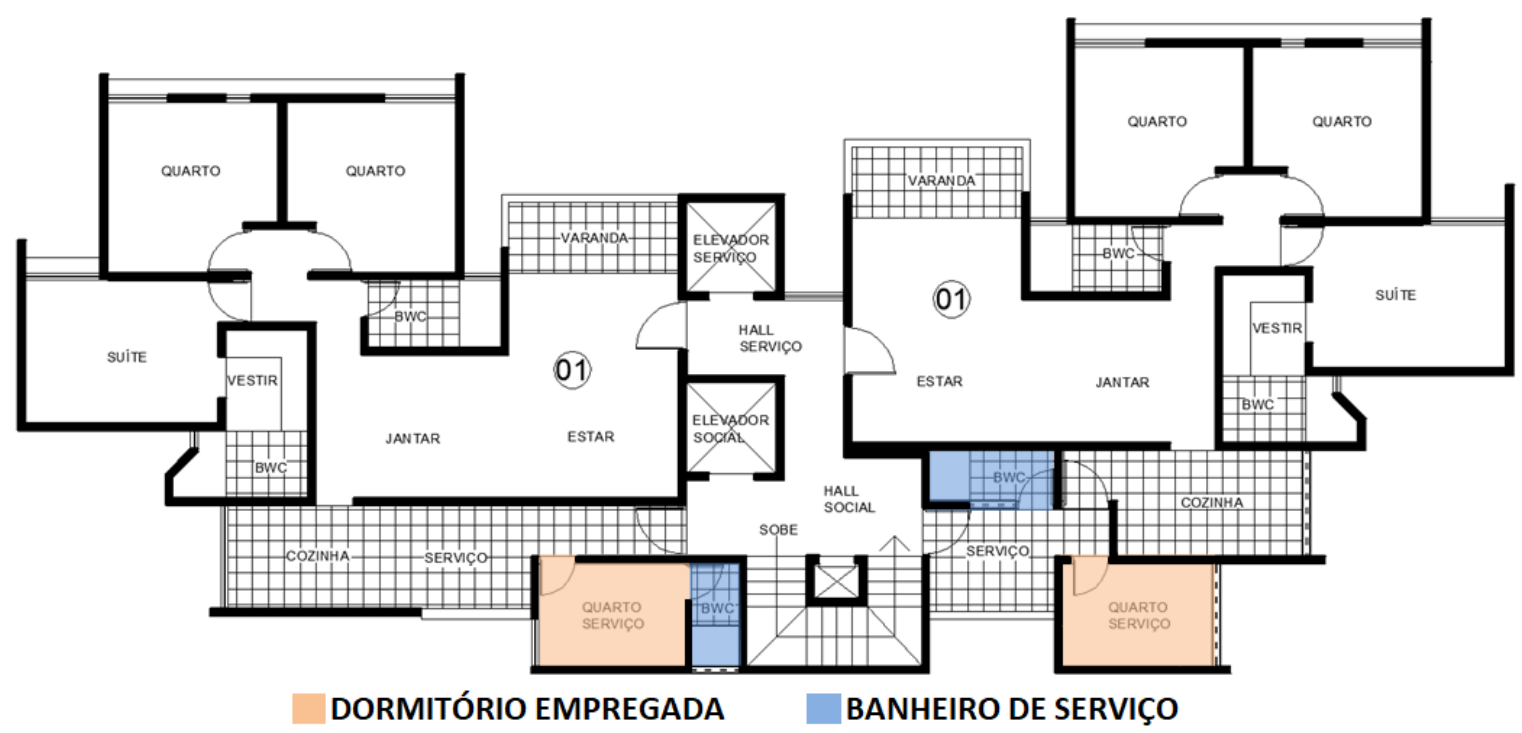

Fonte: adaptado do banco de dados do gEPA.

Nota: sem escala.

20 Lima, J. C. R. de; Toledo, A. M. 
Figura 19 - Planta baixa do pavimento tipo do edifício Erich Fromm (1987)

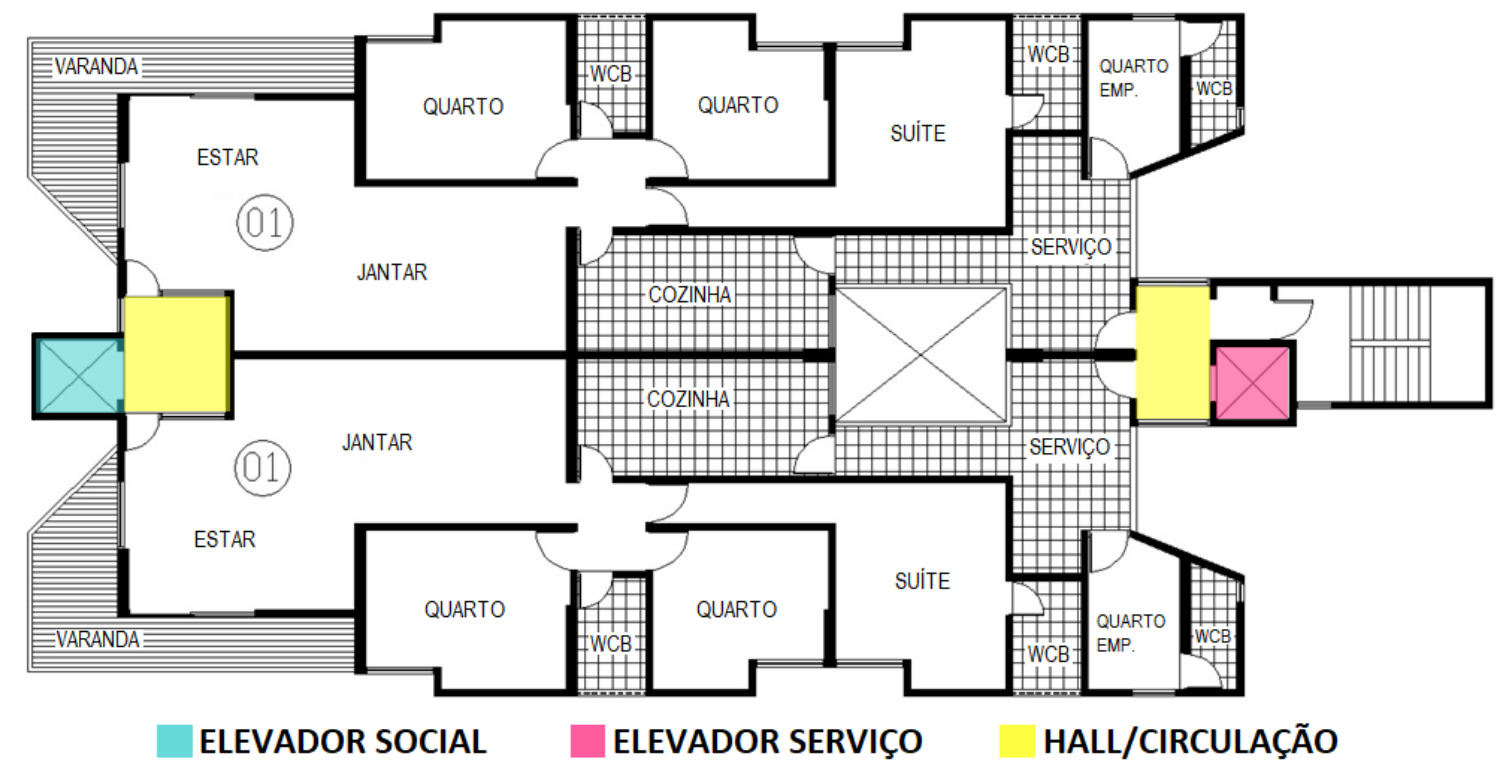

Fonte: adaptado do banco de dados do gEPA.

Nota: sem escala.

Figura 20 - Tipologias de apartamentos no bairro Farol: 1990 a 1999

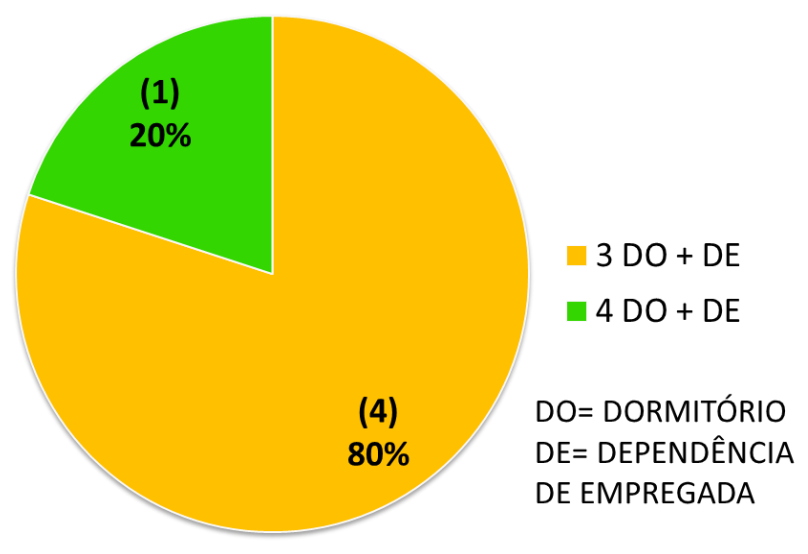

Figura 21 - Planta baixa de unidade do edifício Porchat (1990)

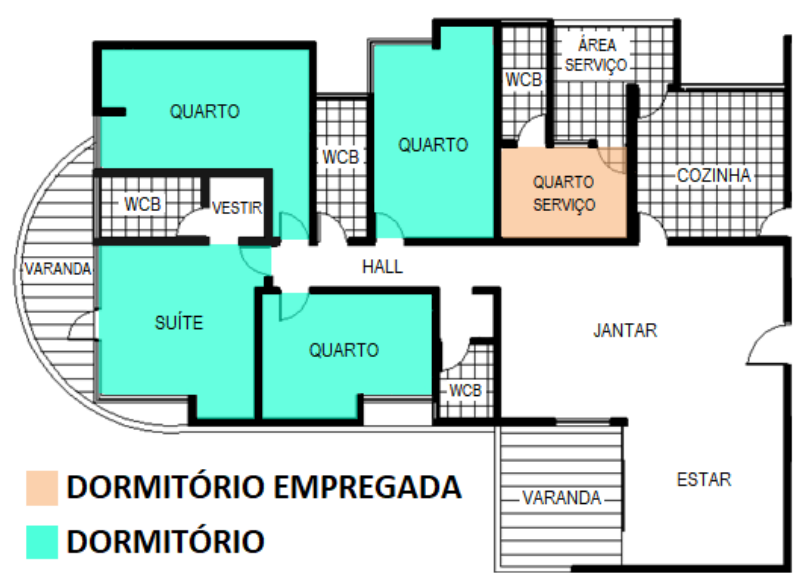

Fonte: adaptado do banco de dados do gEPA.

Nota: sem escala. 
Figura 22 - Planta baixa de unidade do edifício Panorama (1991)

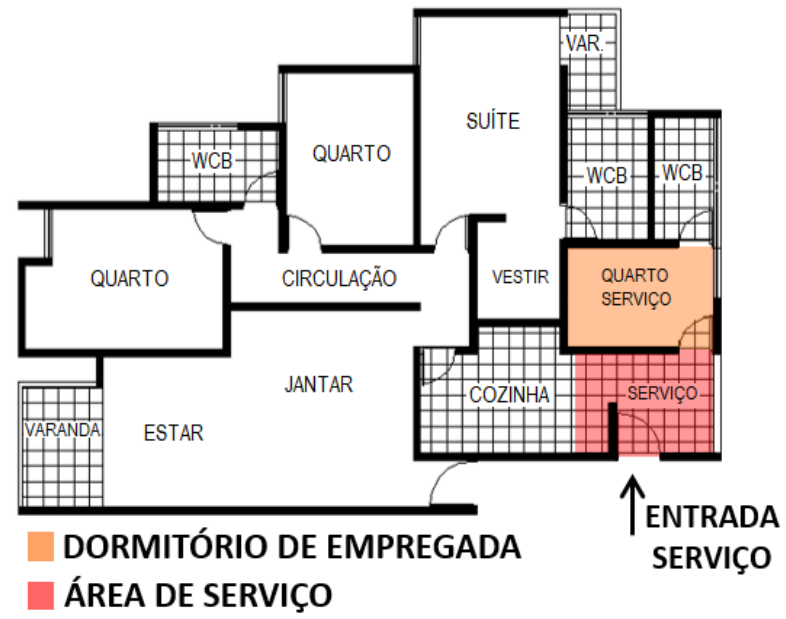

Fonte: adaptado do banco de dados do gEPA.

Nota: sem escala.

Figura 23 - Planta baixa de unidade do edifício Buganvilia (1999)

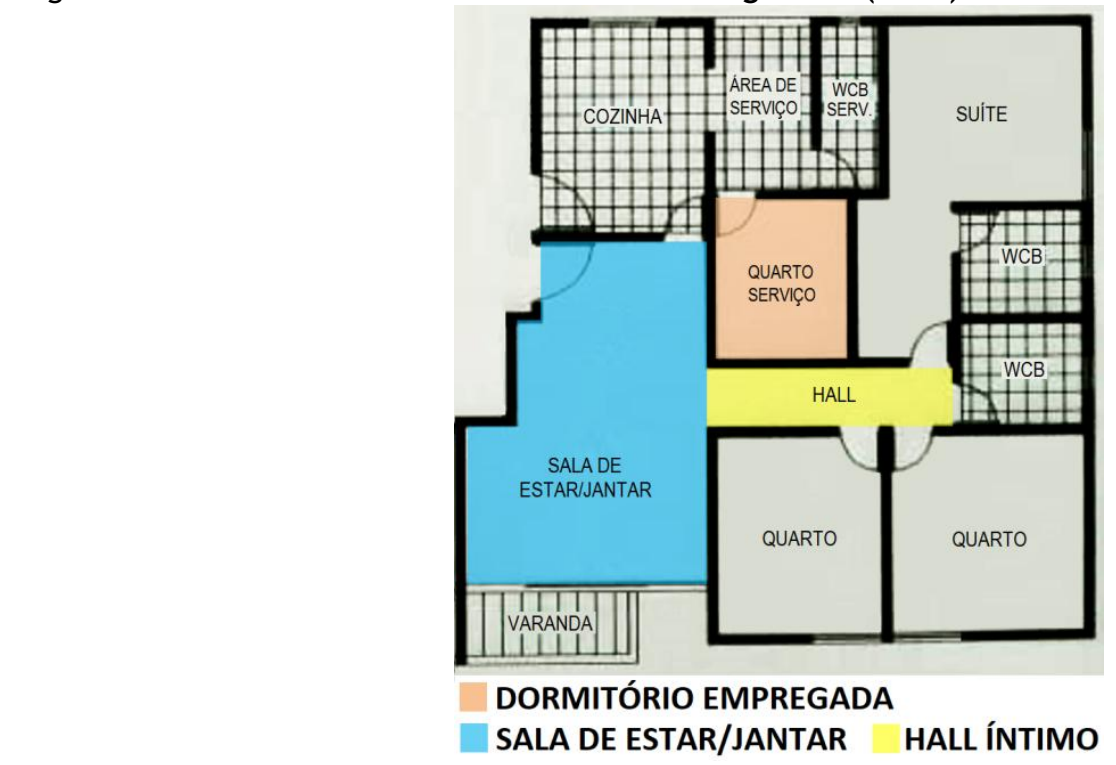

Fonte: adaptado do banco de dados do gEPA.

Nota: sem escala.

\section{Áreas dos dormitórios de empregada}

Na maioria dos edifícios desse período as dependências de empregados apresentaram área dentro do padrão mínimo de $6 \mathrm{~m}^{2}$ (3 unidades - 60\%); os demais exemplares contaram com 5,7 m² de área.

\section{Aberturas dos dormitórios de empregada}

Em relação às janelas, os exemplares apresentaram situação mista ( 2 unidades), janela com abertura para o exterior (1 unidade), janela com abertura para o interior da área de serviço (1 unidade). Apenas nos apartamentos do edifício Buganvilia de 1999 (Figura 23) foram observados dormitórios de empregada destituídos de qualquer tipo de janela.

\section{Localização e áreas dos banheiros de serviço}

Em todos os casos verificou-se a existência do banheiro de serviço (conformando dependência completa de empregada), sendo este disposto ao lado da dependência de empregada ( 2 unidades, $40 \%$ ), na forma de suíte 
(1 unidade, 20\%) e situação mista (2 unidades, 40\%). Além disso, os banheiros de serviço de todos os exemplares apresentaram dimensões dentro do padrão de $2 \mathrm{~m}^{2}$.

\section{Caracterização das entradas e elevadores dos edifícios}

Em relação aos acessos, verificou-se que todos os edifícios apresentaram apartamentos dotados de porta social e de serviço, sendo essas dispostas lado a lado no mesmo hall (4 unidades - 80\%) (Figura 24); e alocadas em halls totalmente separados (1 unidade - 20\%). Em relação aos elevadores, observou-se o predomínio de edifícios dotados de um único elevador (3 unidades - 60\%), sendo os demais exemplares compostos por elevadores social e de serviço posicionados próximos no mesmo hall (1 unidade $-20 \%$ ), e elevadores dispostos em halls totalmente separados (1 unidade - 20\%).

\section{Década de 2000}

\section{Tipologias e padrões construtivos dos edifícios}

Durante a década de 2000 foram construídos 25 edifícios de apartamentos — produção significativamente maior em relação às décadas anteriores. Embora a tipologia de 3 dormitórios com dependência de empregada (7 unidades - 28\%) (Figura 25) continue a dominar o mercado (Figura 26), observa-se nesse período uma quantidade relevante de edifícios com o dormitório reversível (3 unidades - 12\%) e, pela primeira vez no bairro, a construção de edifícios com plantas sem dependência de empregada e sem dormitório reversível (4 unidades $-16 \%$ ).

Considerando apenas o grupo de edifícios dotados de dormitório de empregada (18 unidades - 72\% do total de edifícios da década de 2000), observou-se que a maioria dos exemplares apresentou padrão construtivo alto (12 unidades), sendo os demais edifícios de padrão médio (3 unidades) e padrão luxo ( 3 unidades). Os padrões construtivos "alto" e "luxo", já adotados em décadas anteriores em edifícios dos bairros da orla marítima da cidade, foram novidades implementadas nesse período nos edifícios do bairro Farol.

\section{Localização, acesso e flexibilidade de abertura dos dormitórios de empregada}

Em quase todos os casos o dormitório de empregada foi mantido no setor de serviço e com acesso realizado pela área de serviço, sendo exceção o edifício Palazzo Maggiore de 2003 (Figura 27), cujo acesso a esse ambiente ocorre através de um hall interno ligado ao acesso externo (porta de serviço). O edifício Mansão Antônio Soares de 2010 (Figura 28) apresenta uma situação inusitada em relação à forma de acesso ao dormitório de empregada, em virtude da existência de uma porta que liga diretamente o setor de serviço ao hall íntimo onde se encontram os demais dormitórios do apartamento, o que possibilita uma segunda forma de acesso ao dormitório de empregada.

Figura 24 - Planta baixa tipo do edifício Thomaz Cavalcante (1999)

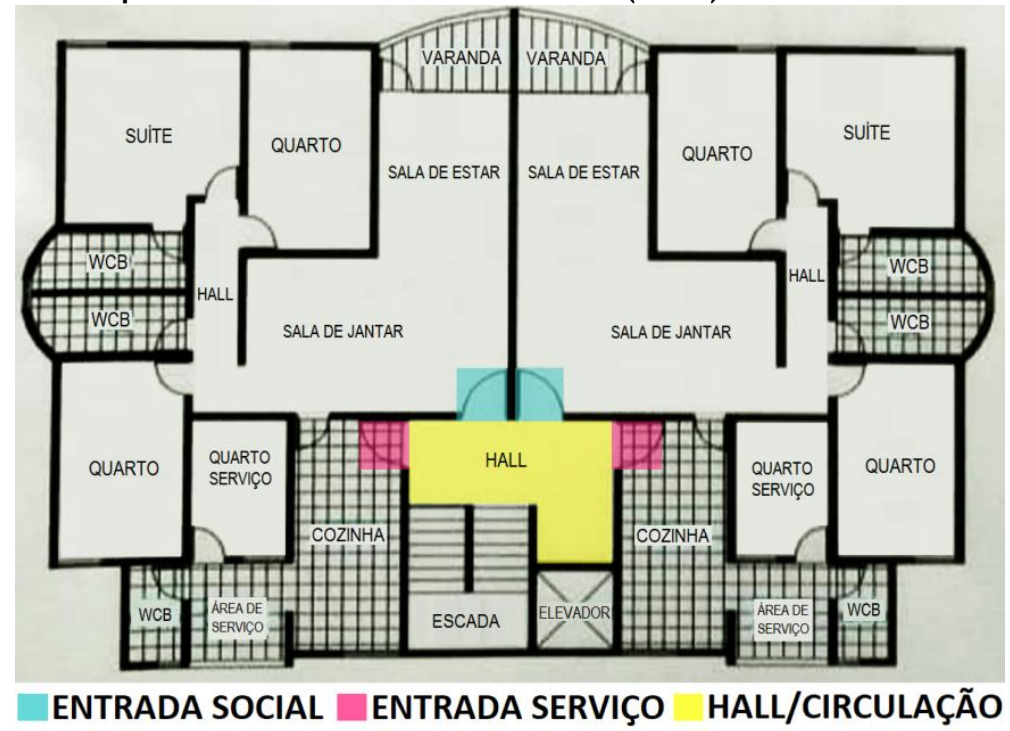

Fonte: adaptado do banco de dados do gEPA.

Nota: sem escala. 
Figura 25 - Tipologias de apartamentos no bairro Farol: 2000 a 2010

(1)

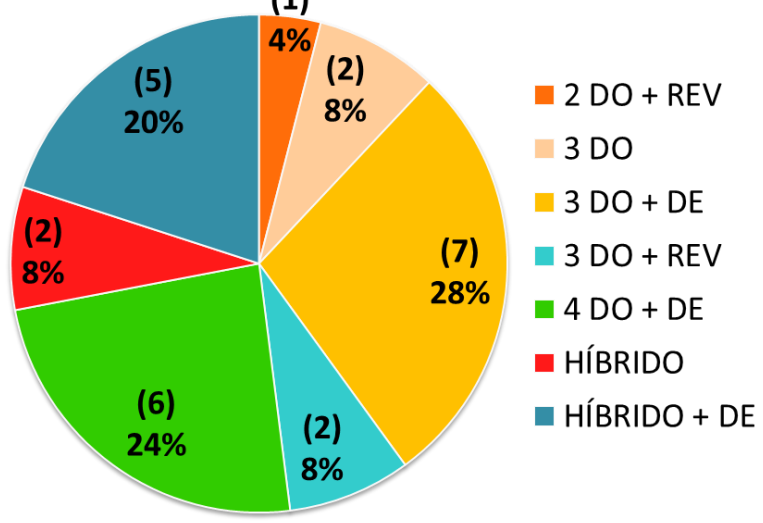

Figura 26 - Planta de unidade do edifício Carrion de Los Condes (2002)

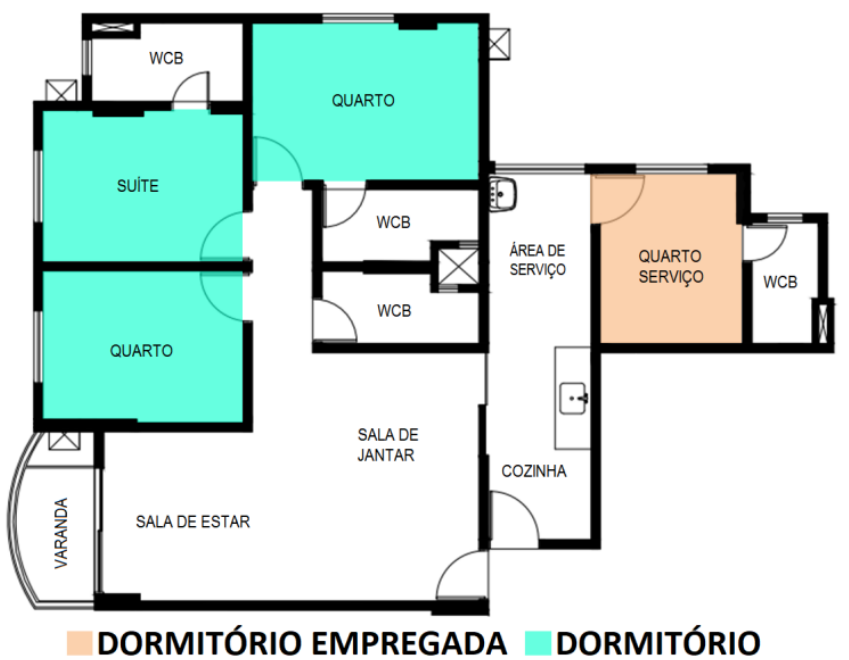

Fonte: adaptado do banco de dados do gEPA.

Nota: sem escala.

Figura 27 - Planta baixa de unidade do edifício Palazzo Maggiore (2003)

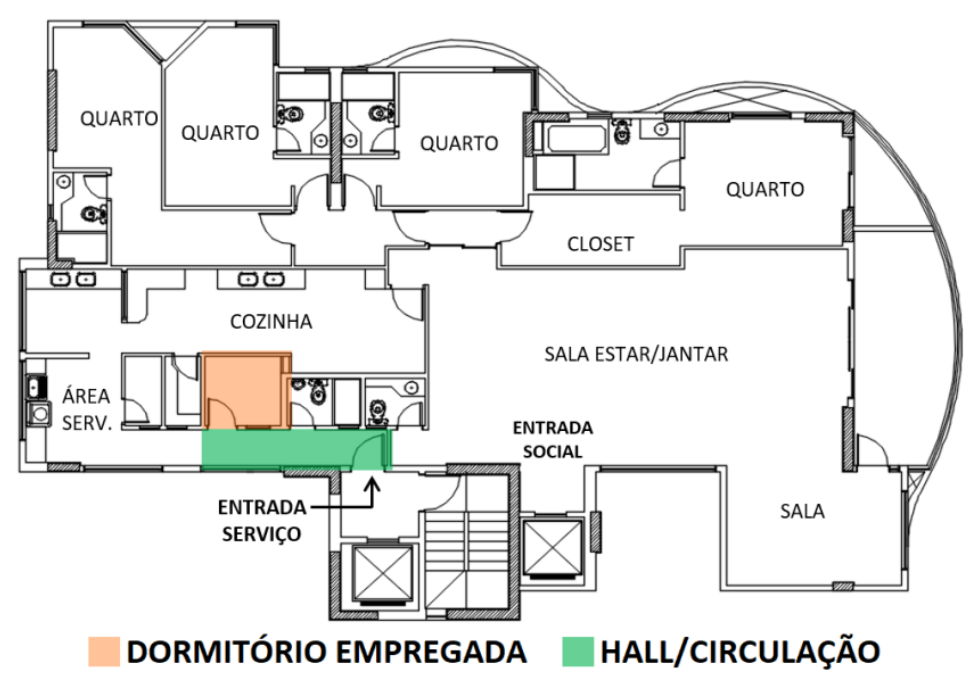

Fonte: adaptado do banco de dados do gEPA.

Nota: sem escala.

24 Lima, J. C. R. de; Toledo, A. M. 
Figura 28 - Planta baixa de unidade do edifício Mansão Antônio Soares (2010)

Fonte: adaptado do banco de dados do gEPA.

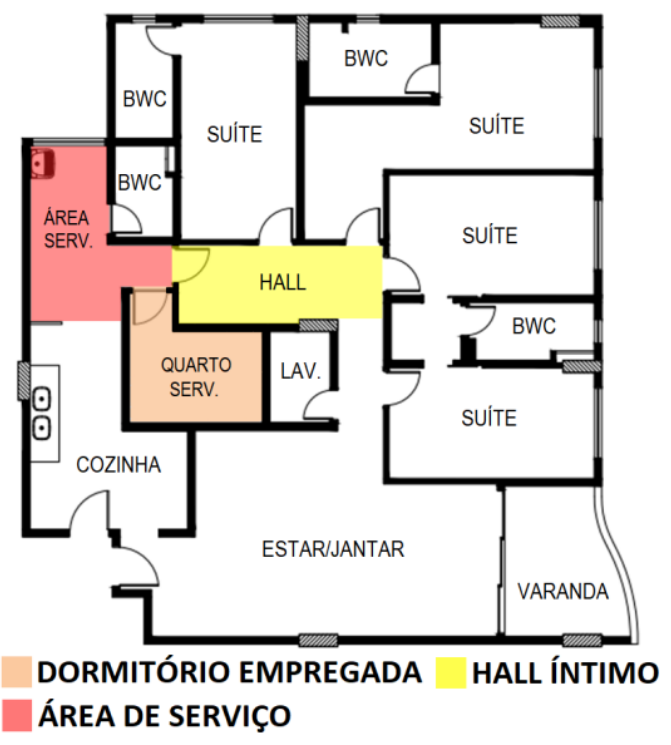

Nota: sem escala.

$\mathrm{Na}$ maioria dos casos o dormitório de empregada não apresentou flexibilidade de planta (8 unidades 44,4\%). Os demais exemplares apresentaram situação mista (6 unidades, 33,3\%), possibilidade de abertura para o setor íntimo ( 2 unidades, 11,1\%), possibilidade de abertura para o setor social (1 unidade, 5,5\%) e abertura para os setores social e íntimo (1 unidade, 5,5\%).

\section{Áreas dos dormitórios de empregada}

$\mathrm{Na}$ maioria dos edifícios desse período os dormitórios de empregada apresentaram área inferior a $6 \mathrm{~m}^{2}(14$ unidades $-77,8 \%$ ). Verificou-se nos apartamentos do edifício Terrazos de 2008 o dormitório de empregada com menor área desse período $\left(3,2 \mathrm{~m}^{2}\right)$ (Figura 29).

\section{Aberturas dos dormitórios de empregada}

Em relação às janelas, os edifícios de apartamentos apresentaram dormitórios de empregada dotados de janela única com abertura para o interior da área de serviço ( 8 unidades $-44,4 \%$ ); janela com abertura para o exterior (7 unidades - 38,9\%); e situação mista (3 unidades - 16,7\%) (Figuras 30 e 31).

\section{Localização e áreas dos banheiros de serviço}

Todos os casos de edifícios de apartamentos com dormitório de empregada apresentaram banheiro de serviço, constituindo assim dependência completa. Verificou-se que o banheiro de serviço ocupou as seguintes posições: disposto ao lado do dormitório ( 9 unidades, 50\%), em forma de suíte (4 unidades, $22,2 \%$ ), situação mista (4 unidades $-22,2 \%$ ), e distante do dormitório (1 unidade, 5,6\%). Além disso, os banheiros de serviço da maioria dos edifícios contaram com áreas dentro do padrão de $2 \mathrm{~m}^{2}$ (14 unidades $77,8 \%$ ). O menor banheiro de serviço do período apresentou área de 1,4 m².

\section{Caracterização das entradas e elevadores dos edifícios}

Em relação às entradas dos apartamentos, observou-se que a maioria dos edifícios de apartamentos com dormitório de empregada apresentou porta social e de serviço, sendo essas dispostas lado a lado no mesmo hall (8 unidades $-44,4 \%$ do total de 18 unidades); alocadas em halls totalmente separados (6 unidades $33,3 \%)$; separadas, porém acessadas pelo mesmo hall de circulação (1 unidade $-5,6 \%$ ) e situação mista (1 unidade $-5,6 \%)$. Apenas 2 edifícios $(11,1 \%)$ apresentaram apartamentos dotados de uma única entrada.

Além disso, todos os edifícios de apartamentos dotados de dormitório de empregada desse período contaram com diferenciação de elevadores pelo uso social e serviço, sendo esses posicionados próximos no mesmo hall (7 unidades - 38,9\%); dispostos em halls totalmente separados (7 unidades $-38,9 \%$ ), e alocados em halls distintos que se interligam (4 unidades $-22,2 \%)$. 
Figura 29 - Planta baixa de unidade do edifício Terrazos (2008)

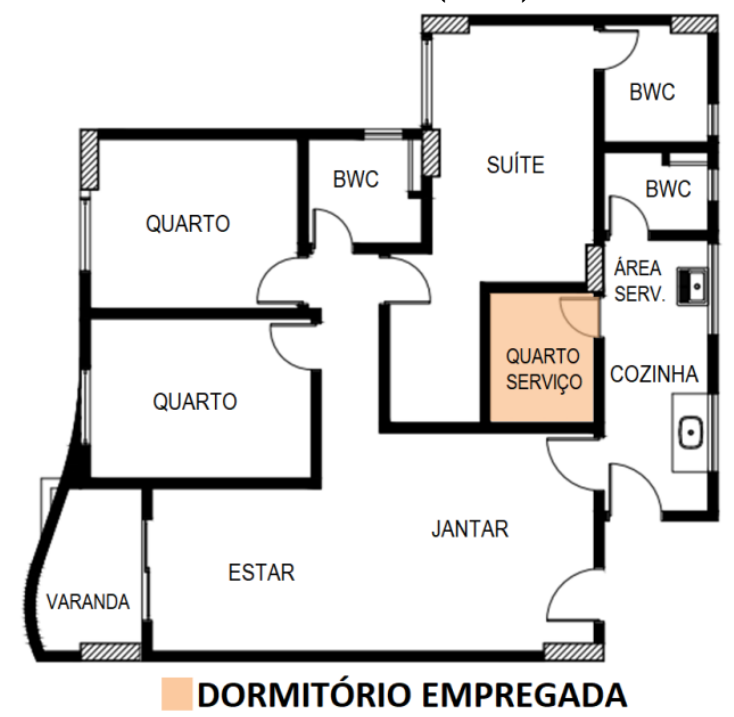

Fonte: adaptado do banco de dados do gEPA.

Nota: sem escala.

Figura 30- Planta baixa tipo do edifício Phoenix (2004)

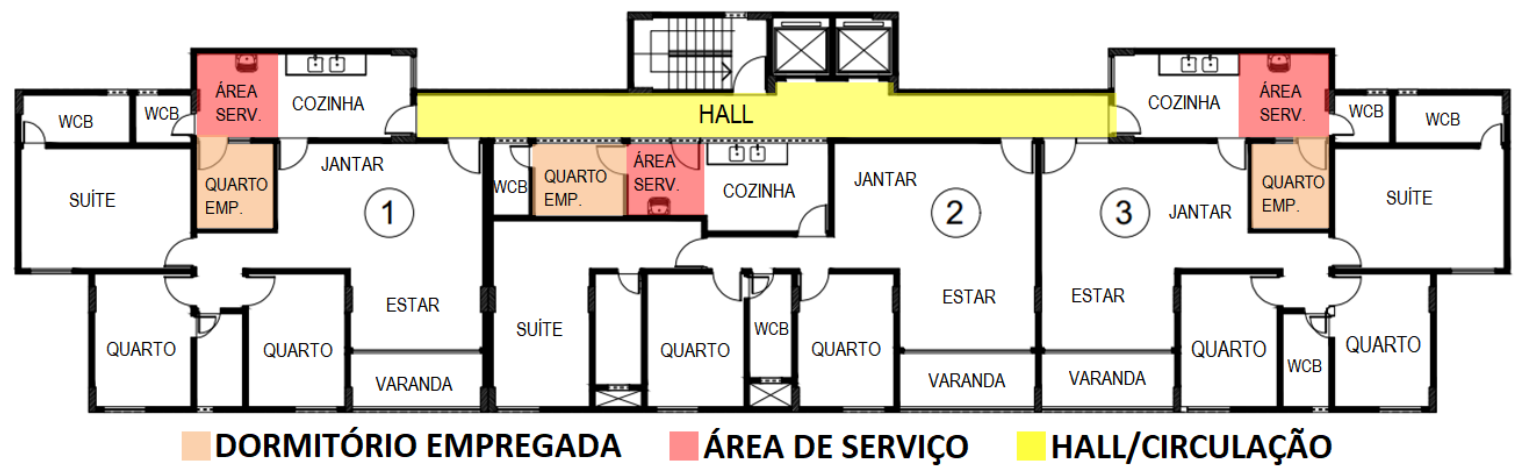

Fonte: adaptado do banco de dados do gEPA. Nota: sem escala.

Figura 31 - Planta baixa tipo do edifício Piazza Bella Vista (2001)

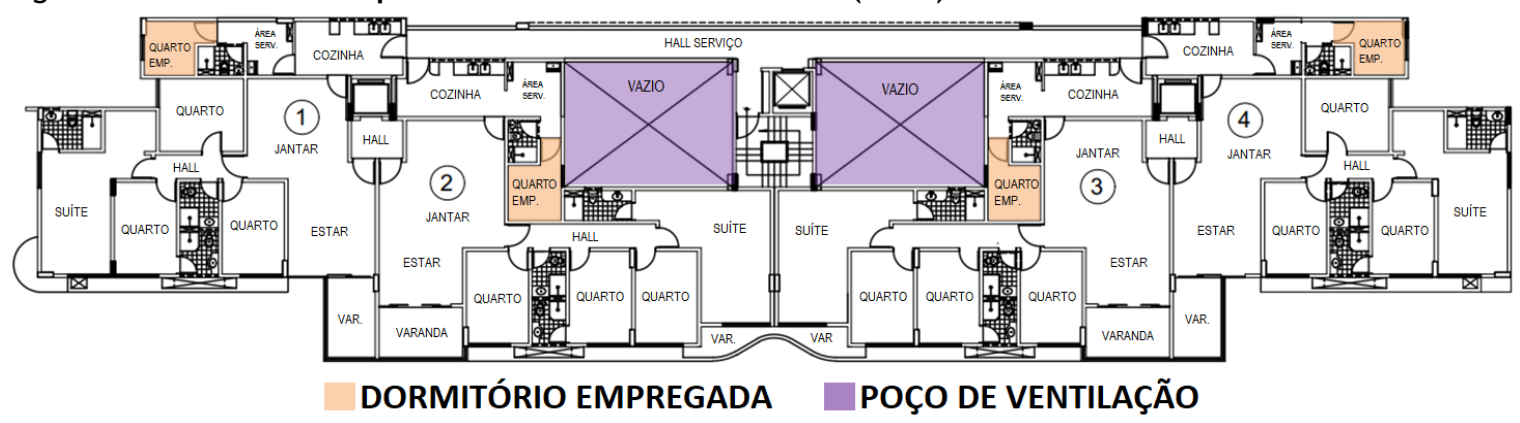

Fonte: adaptado do banco de dados do gEPA.

Nota: sem escala.

Em relação aos edifícios de apartamentos dotados de dormitório reversível, a maioria contou com duas portas ( 3 unidades $-75 \%$ do total de 4 unidades) e elevadores social e de serviço ( 3 unidades $-75 \%$ do total de 4 unidades). Todos os três edifícios cujas unidades não apresentavam nenhum tipo de dormitório de serviço, contavam com entrada única, porém elevadores diferenciados pelo uso social e serviço.

26 Lima, J. C. R. de; Toledo, A. M. 


\section{Comparativo entre as décadas}

Em relação à existência de dormitórios de empregadas nos edifícios construídos em cada período, observouse que durante as décadas de 1960 e 1970 100\% da produção de apartamentos apresentou esse ambiente; na década de 1980 esse percentual caiu para 85,7\%, em virtude do lançamento do primeiro edifício de apartamentos com dormitório reversível no bairro; nos anos 1990 100\% dos edifícios lançados apresentavam dormitório de empregada, sendo a tendência de reversibilidade desse espaço não incorporada aos programas de apartamentos desse período. Durante a década de 2000 o dormitório de empregada continuou a ser mantido na grande maioria dos edifícios $(72 \%)$, porém já se observa a construção significativa de tipologias dotadas de dormitório reversível (16\%), e de exemplares destituídos de qualquer tipo de dormitório de serviço $(12 \%)$.

A partir da verificação do padrão construtivo adotado nos edifícios cujas unidades eram dotadas de dormitórios de empregada, foi possível perceber que o padrão construtivo mínimo implementado durante todo o período analisado foi o "médio" (não foram construídos edifícios de padrão médio baixo ou popular, presentes em outros bairros da cidade). Além disso, observou-se ao longo do tempo um aumento do padrão construtivo predominante, sendo até o final da década de 1980, majoritário o padrão "médio", enquanto que na década de 1990 o padrão "médio alto" passou a dominar a produção. Por fim, na década de 2000 as dependências de empregada já não são mais observadas em edifícios de padrão "médio", o padrão construtivo "alto" predomina sobre o conjunto, e são lançados os primeiros apartamentos de padrão "luxo" no bairro.

O dormitório de empregada foi utilizado ao longo dessas décadas em diferentes tipologias de apartamentos, sendo majoritária a tipologia de 3 dormitórios, a qual representou 46,7\% da produção total de 45 edifícios construídos no bairro Farol. No entanto, não foram observadas alterações significativas em relação à configuração espacial desse ambiente nos exemplares analisados, sendo o dormitório de empregada mantido, em geral, no setor de serviço, próximo à área de serviço e sem possibilidade de abertura para os demais setores funcionais da habitação; contando com janela com abertura para o ambiente externo; acompanhado de banheiro de serviço em diferentes situações topológicas; e apresentando variações em suas áreas de acordo com a década analisada.

Durante as décadas de 1960 e 1970, a maior parte dos edifícios apresentou dormitórios de empregada com dimensões menores que o padrão de $6 \mathrm{~m}^{2}$. No entanto, todos os edifícios construídos ao longo dos anos 1980 e a maior parte dos exemplares da década de 1990 apresentaram áreas dentro desse valor mínimo. Nos anos 2000 observa-se novamente a tendência praticada nas primeiras décadas de verticalização na cidade, sendo a grande maioria dos dormitórios de empregada dotada de áreas inferiores ao mínimo.

Em relação ao banheiro de serviço, verificou-se que este fez parte da grande maioria dos programas de apartamentos lançados durante essas cinco décadas (93,3\% do total de 45 edifícios), conformando em conjunto com o dormitório de serviço a dependência completa de empregada (80\% do total de 45 edifícios), e sendo também utilizado junto ao dormitório reversível (6,7\% do total de 45 edifícios) e em tipologias destituídas de qualquer tipo de dormitório destinado à empregada doméstica (6,7\% do total de 45 edifícios). $\mathrm{Na}$ maior parte dos casos analisados esse ambiente apresentou dimensões compatíveis com o padrão mínimo estabelecido.

Em relação à questão dos acessos, observou-se que durante todas as décadas analisadas a solução de apartamentos com duas entradas diferenciadas pelo uso social e serviço foi dominante, sendo pouco significativa a parcela de exemplares dotados de entrada única. Além disso, na maior parte dos casos essas portas foram dispostas muito próximas, sendo acessadas pelo mesmo hall de circulação. A preferência por parte das construtoras na execução dessa solução de projeto estava possivelmente relacionada à economia promovida pela construção de uma única circulação, ou seja, a partir da redução das áreas de uso comum do edifício.

Sobre a questão dos elevadores, observou-se a existência de uma grande variação de soluções nos empreendimentos das décadas de 1960 e 1970, possivelmente em virtude do caráter ensaístico dessa primeira produção, a partir da qual os agentes do mercado buscavam entender quais soluções teriam maior aceitação pelo público. Essa diversidade continuou presente na década seguinte, porém nos anos 1990 a maior parte dos exemplares contou com apenas um elevador. Nos anos 2000 quase todos os edifícios construídos no bairro apresentam dois ou mais elevadores, sendo estes, em geral, dispostos próximos no mesmo hall ou totalmente separados em halls independentes. 


\section{Conclusão}

A análise das plantas dos apartamentos do bairro Farol, em Maceió, AL, revelou que a dependência de empregada foi elemento marcante do modo de morar da população local de renda média e alta do bairro, estando presente em seu formato "tradicional" (destituído do caráter de reversibilidade) em quase todos os edifícios lançados entre as décadas de 1960 e 1990, sobretudo na tipologia de apartamentos de 3 dormitórios.

Um dos fatores que contribuiu para a produção e manutenção da dependência de empregada (dormitório e banheiro) na maior parte dos projetos de apartamentos ofertados pelo setor imobiliário desse período no bairro foi a existência prévia de uma cultura de contratação de empregadas domésticas pelas famílias dessas faixas de renda, sendo grande parte dessa mão de obra composta por mulheres pobres do interior que pernoitavam no serviço. Possivelmente, a ampla oferta de mão de obra doméstica associada à inexistência ou descumprimento, durante muito tempo, de leis de âmbito nacional que regulamentassem a prestação desse serviço, fortaleceram essa cultura.

Nos anos 2000 os edifícios de apartamentos contendo dependência de empregada predominaram sobre uma produção composta também por exemplares dotados de dormitório reversível e edifícios destituídos de qualquer tipo de dormitório de serviço. O banheiro de serviço permaneceu na grande maioria dos edifícios, sendo de fato priorizado nos programas de necessidades de quase todas as tipologias de apartamentos, e por vezes desvinculado do dormitório de serviço.

Desse modo, o fenômeno de supressão das dependências de empregadas dos programas dos apartamentos de edifícios lançados no bairro Farol tem se revelado ainda bastante reduzido, embora durante a década de 2000 já se observe uma tendência de restrição desses ambientes a edifícios direcionados à população mais abastada, de maneira que a classe média vai deixando de ser um dos públicos-alvos.

A mudança mais significativa em relação aos dormitórios de empregadas analisados foi quanto ao dimensionamento do ambiente, observando-se na última década tendência de se produzir espaços inferiores ao mínimo estabelecido nas legislações anteriores. A negligência em relação aos parâmetros de qualidade espacial do dormitório de empregada pode estar relacionada a uma visão preconceituosa dos agentes produtores de habitações (arquitetos, construtoras, etc.) sobre a trabalhadora doméstica; ou mesmo ao entendimento de que o quarto de serviço em geral perdeu a sua função original de local de descanso ou pernoite da empregada para se tornar apenas espaço de armazenagem de alimentos ou objetos.

Tendo em mente que a produção de edifícios de apartamentos destituídos de dependência de empregada no bairro Farol só se tornou significativa na década de 2000, conclui-se que as mudanças anunciadas pela aprovação da Lei n. 5859/72 e da legislação trabalhista de 1988 não alteraram de maneira expressiva a oferta imobiliária direcionada às famílias alagoanas de renda mais elevada.

Sugere-se ampliar a análise dos exemplares lançados nos demais bairros da cidade de Maceió, no período de 2011 a 2019 - marcado pela aprovação da Emenda Constitucional n. 72 em 2 de abril de 2013 e que ficou conhecida popularmente como "PEC das domésticas", e da Lei Complementar n. $150 \mathrm{em} 1^{\circ}$ de junho de 2015, que ampliaram o rol de direitos das empregadas domésticas, e que, aliadas a outras mudanças socioeconômicas, podem ter exercido influência sobre a forma como o mercado imobiliário passou a planejar as dependências de serviço dos empreendimentos construídos nesse período na cidade.

\section{Referências}

ALVES, M. E. M. O início da verticalização em Maceió-AL: um estudo tipológico dos edifícios multifamiliares em altura (1960-1970). Maceió, 2012. Dissertação (Mestrado em Arquitetura e Urbanismo) Faculdade de Arquitetura e Urbanismo da Universidade Federal de Alagoas. Maceió, 2012.

BARROS, P. Farol é a parte alta com mais investimentos do setor imobiliário. Gazeta de Alagoas, Maceió, 30 out. 2014.

BITTAR, W. S. M; VERÍSSIMO, F. S. 500 anos da casa no Brasil: as transformações da arquitetura e da utilização do espaço da moradia. 2. ed. Rio de Janeiro: Ediouro. 1999.

BRANDÃO, D. Q. Diversidade e potencial de flexibilidade de arranjos espaciais de apartamentos. Florianópolis, 2002. Tese (Doutorado em Engenharia de Produção) - Programa de Pós-Graduação em Engenharia de Produção, Universidade Federal de Santa Catarina, Florianópolis, 2002.

BRASIL. Constituição (1988). Constituição da República Federativa do Brasil. Brasília, 1988. 
BRASIL. Constituição (1988). Emenda Constitucional n. 72 de 02 de abril de 2013. Brasília, 2013.

BRASIL. Constituição (1988). Lei n 5.859, de 11 de dezembro de 1972. Brasília, 1972.

CARVALHO, M. J. M. De portas adentro e de portas afora: trabalho doméstico e escravidão no Recife, 1822-1850. Afro-Ásia, v. 29/30, p. 41-78, 2003.

COIMBRA, T. S. et al. Condições da orientação em planta das dependências de empregada nos edifícios residenciais multifamiliares em Maceió/AL. Ímpeto, v. 8, p. 28-35, 2018.

CORONATO, M. et al. Por que a empregada sumiu? Revista Época, jan. 2012. Disponível em: http://revistaepoca.globo.com/vida/noticia/2012/01/por-que-empregada-sumiu.html. Acesso em: 15 jan. 2020.

FORTES, C. N. R. Para além dos navegantes: o farol de Maceió (1827-1951). Dissertação (Mestrado em Arquitetura e Urbanismo) - Faculdade de Arquitetura e Urbanismo, Universidade Federal de Alagoas, Maceió, 2011.

GOLDSTEIN, D. The aesthtics of domination: class, culture, and the lives of domestic workers. In: LAUGHTER out of place: Race, class and sexuality in a rio Shanytown. Berkeley: University of California Press, 2003.

INSTITUTO DE PESQUISA APLICADA. Retrato das desigualdades de gênero e raça - 1995 a 2015. Brasília, 2015.

LEMOS, C. B.; SCHETTINO, P. T. J. “O Palacete Carioca”: estudo sobre a relação entre as transformações da arquitetura residencial da elite e a evolução do papel social feminino no final do século XIX e início do século XX no Rio de Janeiro. In: MENDONÇA, I.; CARITA, H.; MALTA, M. A casa senhorial em Lisboa e no Rio de Janeiro: anatomia dos interiores. Rio de Janeiro: UFRJ, 2014.

LEMOS, C. Cozinhas, etc:um estudo sobre as zonas de serviço da casa paulista. 2. ed. São Paulo: Perspectiva, 1978.

LIMA, J. C. R. Pela porta de serviço: análise espacial das dependências de empregadas dos edifícios de apartamentos nas décadas de 1960-1990 na cidade de Maceió/AL. Maceió, 2019. 194 f. Dissertação (Mestrado em Arquitetura: Dinâmica do Espaço Habitado) - Faculdade de Arquitetura, Programa de Pós Graduação em Arquitetura e Urbanismo, Universidade Federal de Alagoas, Maceió, 2019.

LIMA, J. C. R.; TOLEDO, A. M. A permanência do dormitório da empregada nos apartamentos: estudo comparativo nas décadas de 1960 a 1990 em Maceió/AL. Gestão \& Tecnologia de Projetos, v. 13, p. 7996, 2018.

LOPEZ, C. L. A. Empregadas domésticas: experiências do exercício da atividade. Maceió, 2018. 189 f. Dissertação (Mestrado em Sociologia) - Instituto de Ciências Sociais, Universidade Federal de Alagoas, Maceió, 2018.

MACEIÓ. Lei n. 3.537, de 23 de dezembro de 1985, que institui o código de edificações de Maceió e dá outras providências. Diário Oficial do Município, Maceió, 1985.

MELLO, B. C. E. E o negro na arquitetura brasileira? Arquitextos, São Paulo, v. 13, n. 145.01, jun. 2012.

MORAIS, F. O. O quartinho: a dependência doméstica na habitação multifamiliar na cidade de João Pessoa (PB) no século XXI. Dissertação (Mestrado em Arquitetura e Urbanismo), Universidade Federal da Paraíba, João Pessoa, 2017.

NEUFERT, E. Arte de projetar em arquitetura. 17. ed. Barcelona: Ed. Gustavo Gili,2008.

ORGANIZAÇÃO INTERNACIONAL DO TRABALHO. O trabalho doméstico no Brasil: rumo ao reconhecimento institucional. Brasília, 2010.

SALEIRO FILHO, M. O. A dependência da dependência de empregado: de espaço segregado a espaço invertido? Rio de Janeiro, 2001. Dissertação (Mestrado em Arquitetura) - Faculdade de Arquitetura e Urbanismo, Universidade Federal do Rio de Janeiro, Rio de Janeiro, 2001.

SANTOS, F. J. Análise tipológica dos edifícios multifamiliares no bairro do Farol- Maceió /AL (20002010). Maceió, 2016. 218 f. Dissertação (Mestrado em Arquitetura e Urbanismo) - Faculdade de Arquitetura e Urbanismo, Universidade Federal de Alagoas, Maceió, 2016. 
SILVA, L. O. Os quintais e a morada brasileira. Cadernos de Arquitetura e Urbanismo, Belo Horizonte, v. 11, n. 12, p. 61-78, dez. 2004.

SOUZA, F. F. Entre a convivência e a retribuição: trabalho e subordinação nos significados sociais da prestação de serviços domésticos (cidade do Rio de Janeiro, 1870-1900). Revista de História Comparada, Rio de Janeiro, v. 4/1, p. 93-125, 2010.

TOLEDO, A.; SILVA, B.; BARBOSA, M. Verticalização na cidade de Maceió: estudo de tipologias de edifícios multifamiliares (1986 a 1992). In: SIMPÓSIO BRASILEIRO DE QUALIDADE DO PROJETO NO AMBIENTE CONSTRUÍDO, Viçosa, 2015. Anais [...] Viçosa: Universidade Federal de Viçosa, 2015.

TRAMONTANO, M.; VILLA, S. Apartamento metropolitano: evolução tipológica. In: SEMINÁRIO HISTÓRIA DA CIDADE E DO URBANISMO, 2000, Natal. Anais [...] Natal: UFRN, 2000.

\section{Jéssica Caroline Rodrigues de Lima}

Faculdade de Arquitetura e Urbanismo | Universidade Federal de Alagoas | Av. Lourival Melo Mota, Tabuleiro do Martins | Maceió - AL Brasil | CEP 57072-970 | Tel.: (82) 3214-1284 | E-mail: jessi.rodrigues90@hotmail.com

\section{Alexandre Márcio Toledo}

Faculdade de Arquitetura e Urbanismo | Universidade Federal de Alagoas | E-mail: prof.amtoledo@gmail.com

\section{Ambiente Construído}

Revista da Associação Nacional de Tecnologia do Ambiente Construído Av. Osvaldo Aranha, $99-3^{\circ}$ andar, Centro

Porto Alegre - RS - Brasil

$$
\text { CEP } 90035-190
$$

Telefone: +55 (51) 3308-4084

Fax: +55 (51) 3308-4054

www.seer.ufrgs.br/ambienteconstruido

E-mail: ambienteconstruido@ufrgs.br 